\title{
EFEITO DE NÍVEIS DE ENERGIA, PROTEÍNA E FORMA FÍSICA DO CONCENTRADO SOBRE O DESEMPENHO DE COELHOS EM CRESCIMENTO
}

\author{
FRANCISCO ALBERTO CORTEZ LANDAETA \\ Engenheiro Agrônomo
}

Orientador: PROF. DR. CYRO FÚLVIO ZINSLY

\begin{abstract}
Dissertação apresentada à Escola Superior de Agricultura "Luiz de Queiroz", da Universidade de São Paulo, para obtenção do título de Mestre em Agronomia, Área de Concentração: Ciência Animal e Paštagens.
\end{abstract}

P I R A C I C A B A

Estado de São Paulo - Brasil

Outubro - 1996 


\section{Dados , Internacionais de Catalogacão pa-Ruhlicasão (GLP) DIVISÃO DE BIBLIÓTÉCA E DOCUMENTAÇĀO - Campus "Luiz de Queiroz"/USP \\ Cortez Landaeta, Francisco Alberto \\ Efeito de niveis de energia, proteina e forma fisica do concentrado sobre o desempenho de coelhos em crecimento / Francisco Alberto Cortez Landaeta. - - Piracicaba, 1996. \\ 70 p. : il. \\ Dissertaçāo (mestrado) - - Escola Superior de Agricultura Luiz de Queiroz, 1996. Bibliografia. \\ 1. Coelho - Alimentaçāo 2. Coelho - Crescimento 3. Raçāo para coelho I. Titulo}

CDD 636.9322 


\section{EFEITO DE NÍVEIS DE ENERGIA, PROTEÍNA E FORMA FÍSICA DO CONCENTRADO SOBRE O DESEMPENHO DE COELHOS EM CRESCIMENTO}

FRANCISCO ALBERTO CORTEZ LANDAETA

Aprovada em: 27.11 .1996

Comissão Julgadora:

Prof. Dr. Cyro Fúlvio Zinsly

ESALQ - USP

Prof. Dr. Ronaldo Dessimoni Carregal

UNESP - JABOTICABAL

Prof. Dr. Wilson Roberto Soâres Mattós

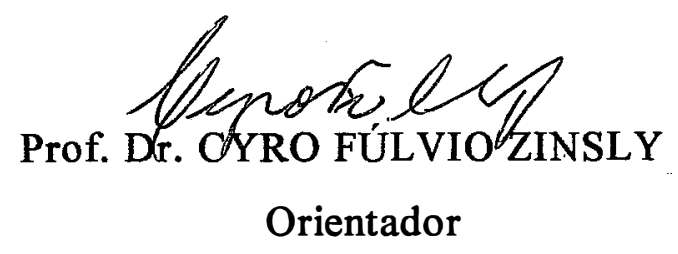


"De olhos vermelhos, de pêlo branquinho, de um pulo bem leve, eu sou o coelhinho.

Sou muito apressado, porém sou guloso, por uma cenoura, já fico manhoso.

Eu salto pra frente, eu salto pra trás, dou mil cambalhotas, sou forte demais.

Comi uma cenoura com casca e tudo, tão grande ela era ... fiquei barrigudo." 
A mis padres Rosita y Luis Cortez,simplemente por TODO,

a mis hermanos Luis, Carlos y Rachel, por todo el cariño y amistad,

a Papi y a mi Abuelito, por nunca dejarme solo,

a Mami y a mi Abuelita, por la creación de la familia,

y a toda la familia por lo especial que cada uno de ellos es.

\section{DEDICO}

A quem me mostrou

a forma mais delicada e doce

de conjugar o verbo

sonhar. 


\section{AGRADECIMENTOS}

- A DEUS, por tudo aquilo que vejo, escuto, falo, sinto e sonho;

- Aos meus pais de coração, Gianette e José Vicente, por todo o apoio e ajuda incondicional mesmo antes de me conhecerem;

- Ao Prof. Dr. Cyro Fúlvio Zinsly pela orientação e criação intelectual deste trabalho, mas principalmente por ser amigo e mestre;

- Ao Prof. Irineu Umberto Packer pela grande ajuda no planejamento e análise estatística deste trabalho;

- Aos Professores do curso de Mestrado em Ciência Animal e Pastagens da ESALQ/USP pelos ensinamentos;

- Aos funcionários do Departamento de Zootecnia da ESALQ/USP, em especial a Cláudia e Vera, pela colaboração e amizade;

- Às funcionárias da Biblioteca Central da ESALQ/USP Kátia e Eliana pela amizade e pelo auxilio durante as revisões para elaboração deste trabalho, assim como ao pessoal do setor de empréstimos;

- Ao funcionário Henrique Chuay (Turquinho) pela grande ajuda na realização deste trabalho;

- Aos meus amigos do curso de Mestrado por compartilhar e dividir momentos muito alegres e outros não tanto; 
- A Alessandra (Molinha), Carla, Marisa, Maria Inés, Cristina, Luciana, Carlos, Artur, Bruno, Paulo, etc., pela amizade, carinho, chopps e apoio nos momentos dificeis;

- A Fátima Aparecida Ribeiro (Jukira), minha "pequena" estagiária, pela GRANDE ajuda durante o experimento, pela música e principalmente pela grande amizade.

- A Rubem e Valba, pela amizade e por nos ensinar que: “Nada está perdido enquanto houver ilusão por encontrá-lo " (Santo Agostinho);

- A Paula e C.B. pela amizade e pelas correrias na hora das copias;

- À CAPES pela concessão da bolsa de estudos;

- A Piracicaba, grande cidade, morada de paz e felicidade;

- Ao Brasil pelos nove anos mais recentes da minha vida. 
Página

RESUMO iv

SUMMARY vii

1. INTRODUÇÃO 1

2. REVISÃO DE LITERATURA 4

2.1. Níveis de energia 4

2.2. Níveis de proteína 8

2.3. Forma física da ração 11

2.4. Uso de rações concentradas 15

2.5. Alimento volumoso 18

2.5.1. Uso de forragens como alimento suplementar 18

2.5.2. Uso do rami (Bohemeria nivea) 22 


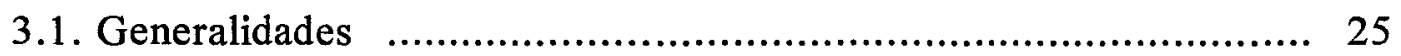

3.2. Alimentação dos animais $\quad$....................................... 27

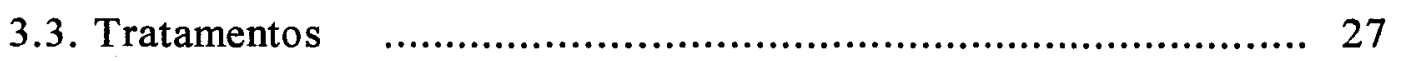

3.4. Rações experimentais ................................................. 28

3.5. Variáveis estudadas $\quad$................................................... 29

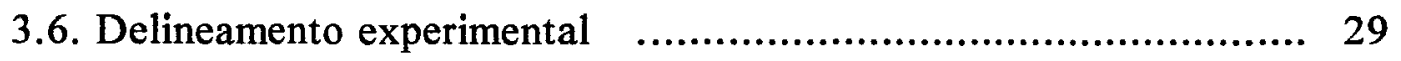

3.7. Custo dos concentrados experimentais ............................. 29

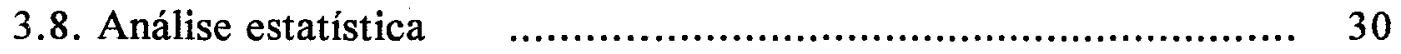

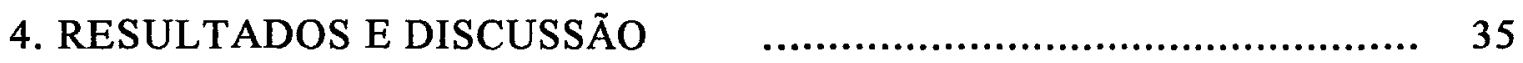

4.1. Ganho diário de peso ............................................... 35

4.1.1. Efeito dos níveis de energia $\quad$............................ 36

4.1.2. Efeito dos níveis de proteína $\quad$.......................... 40

4.1.3. Efeito da forma física do concentrado ...................... 42

4.2. Consumo diário de ração $\quad$............................................ 42

4.2.1. Efeito dos niveis de energia $\quad$............................. 45

4.2.2. Efeito dos níveis de proteína $\quad$............................ 48

4.2.3. Efeito da forma física do concentrado '...................... 49

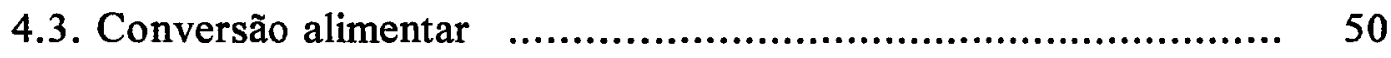

4.3.1. Efeito dos níveis de energia $\quad$........................... 53

4.3.2. Efeito dos níveis de proteína $\quad$........................... 55 
4.3.3. Efeito da forma física do concentrado

4.4. Mortalidade

4.5. Custo do alimento concentrado por $\mathrm{kg}$ de peso vivo

57

5. CONCLUSÕES

60

REFERÊNCIAS BIBLIOGRÁFICAS

62 


\title{
EFEITO DE NÍVEIS DE ENERGIA, PROTEÍNA E FORMA FÍSICA DO CONCENTRADO SOBRE O DESEMPENHO DE COELHOS EM CRESCIMENTO
}

\author{
Autor: FRANCISCO ALBERTO CORTEZ LANDAETA \\ Orientador: PROF. DR. CYRO FÚLVIO ZINSLY
}

\section{RESUMO}

Cento e vinte coelhos de ambos os sexos desmamados aos 35 dias de idade, da raça Nova Zelândia Branco ou mestiços das raças Nova Zelândia Branco e Califórnia, foram alojados individual mente em gaiolas por 35 dias e alimentados à vontade com concentrados contendo níveis de energia $\mathrm{E} 1=2.700$ $\mathrm{kcal} \mathrm{ED} / \mathrm{kg}, \mathrm{E} 2=3.000 \mathrm{kcal} \mathrm{ED} / \mathrm{kg}$ e E3=3.300 $\mathrm{kcal} \mathrm{ED} / \mathrm{kg}$, dois niveis de proteína $\mathrm{P} 1=16 \%$ e $\mathrm{P} 2=20 \%$ e duas formas físicas, farelada e peletizada, suplementadas com rami, com o objetivo de se estudar os efeitos dessas no ganho diário de peso, consumo diário de ração e conversão alimentar.

O delineamento experimental utilizado foi o de blocos casualizados, com esquema fatorial $3 \times 2 \times 2$ em que se estudaram os efeitos dos níveis de energia e proteína e a forma fisica do concentrado. 
A análise da variância revelou efeitos significativos $(\mathrm{P}<0,05)$ para ganho diário de peso, consumo diário de ração e conversão alimentar.

O concentrado contendo $20 \%$ de proteína bruta (PB) e $3.000 \mathrm{kcal} \mathrm{ED/kg}$ propiciou o melhor ganho diário de peso $(36,90 \mathrm{~g})$ enquanto o pior foi aquele contendo $20 \%$ de PB e $2.700 \mathrm{kcal}$ ED/kg apresentou $26,42 \mathrm{~g}$ de ganho de peso por dia.

Para o consumo diário de concentrado, os maiores valores foram observados nos concentrados oferecidos na forma farelada, sendo os tratamentos com nivel de energia de $2.700 \mathrm{kcal} \mathrm{ED} / \mathrm{kg}$ os que apresentaram maior consumo $(114,18$ e $116,28 \mathrm{~g}$ de concentrado por dia, para 16 e $20 \%$ de PB respectivamente). Foi observada a diminuição do consumo de alimento concentrado a medida que se aumentava o nível de energia do mesmo.

Os valores de conversão alimentar tiveram comportamento semelhante aos apresentados pelo consumo de alimento concentrado, tendo sido os maiores valores alcançados por aqueles animais alimentados com os concentrados farelados de baixa energia $(3,85$ e $4,46 \mathrm{~kg}$ de alimento concentrado/ $\mathrm{kg}$ de ganho, para 16 e $20 \%$ de PB respectivamente), já o menor valor foi obtido com o concentrado contendo $3.300 \mathrm{kcal} \mathrm{ED} / \mathrm{kg}$ e $16 \% \mathrm{~PB}(2,29 \mathrm{~kg}$ de alimento concentrado/kg de ganho).

O presente ensaio possibilitou as seguintes conclusões: 
1) É possivel a utilização do sistema alimentar proposto (ração de concentrado suplementada com volumoso).

2) Dentre as formas físicas utilizadas, as rações apresentadas na forma peletizada tiveram um melhor desempenho.

3) O nivel de energia de $3.000 \mathrm{kcal}$ ED/kg apresentou melhor desempenho.

4) O nível $16 \%$ de proteína bruta mostrou-se adequado.

5) $\mathrm{O}$ tratamento com $3.300 \mathrm{kcal} \mathrm{ED} / \mathrm{kg}$ e $16 \%$ de proteína bruta apresentou menor custo de alimento por $\mathrm{kg}$ vivo de coelho produzido.

6) As rações fareladas apresentaram potencial de utilização em criações comerciais. 


\section{THE EFFECT OF ENERGY AND PROTEIN LEVELS AND \\ PHYSICAL FORM OF THE CONCENTRATE ON THE PERFORMANCES OF GROWING RABBITS}

Author: FRANCISCO ALBERTO CORTEZ LANDAETA Adviser: PROF. DR. CYRO FÚLVIO ZINSLY

\section{SUMMARY}

One hundred and twenty White New Zealand or White New Zealand $x$ California crossed rabbits of both sexes were caged individually, during 35 days and fed ad libitum concentrate-based rations with either $2.700 \mathrm{kcal} \mathrm{ED} / \mathrm{kg}, 3.000$ $\mathrm{kcal} \mathrm{ED} / \mathrm{kg}$ or $3.300 \mathrm{kcal} \mathrm{ED} / \mathrm{kg}, 16 \%$ crude protein $(\mathrm{CP})$ or $20 \% \mathrm{CP}$ and two physical forms (pelleted or unpelleted) plus roughage supplementation.

Data were analysed acco-rding to a factorial desing including 3 energy levels, 2 protein levels and 2 physical forms of the concentrate in a randomized blocks model.

The analysis of variance showed some significant effects of the different treatments on total weight gain, food consumption and food conversion.

The conclusions that can be drawn from this trial are: 
1) The proposed feeding system (concentrate-based ration with roughage supplementation) is viable.

2) Among the physical forms tested, pelleted rations showed advantages over tipe unpelleted one.

3) The $3.000 \mathrm{kcal} \mathrm{ED} / \mathrm{kg}$ energy level allowed the best performance.

4) The $16 \%$ crude protein level proved to be adequate.

5) Using the prices of all the rations tested and the feed conversion values, the pelleted ration with $3.300 \mathrm{kcal} \mathrm{ED} / \mathrm{kg}$ and $16 \% \mathrm{CP}$, showed the lowest cost (in $\mathrm{R} \$$ ) per kg liveweight gain.

6) Unpelleted rations seem to be adequate for use in commercial operations. 


\section{INTRODUÇÃO}

Atualmente a criação de coelhos no Brasil atravessa um período de dificuldades, devido principalmente ao elevado preço de comercialização da carne. Enquanto no mercado internacional, a carne refrigerada é cotada a US\$ 3,30 por kilo (Colin \& Lebas, 1994), no mercado interno ela é vendida entre R\$ 6,00 e $\mathrm{R} \$ 8,00$ por $\mathrm{kg}$, afastando desta forma os consumidores eventuais, ficando o mercado restrito apenas àqueles tradicionais. Por outro lado, a concorrência da carne de outras espécies a preços bem mais atrativos, tem mantido o setor cunícula estagnado ou em retrocesso.

Neste sentido, as pesquisas voltam-se para aqueles fatores com capacidade de diminuir os custos de produção, entre os quais encontra-se: a melhoria da qualidade genética dos animais utilizados na reprodução, o que proporcionará benefícios a longo prazo; a mão-de-obra, que no caso brasileiro e de outros países em desenvolvimento está formada principalmente de mão-deobra familiar ou pouco especializada; a redução de custos com instalações e equipamentos, sendo que este fator não teria grande influência, pois já existe uma preocupação com a utilização de materiais de baixo custo nas instalações; e a 
alimentação, responsável por aproximadamente $80 \%$ do custo de produção, e o ponto principal para o qual se concentram as pesquisas.

Nota-se que de forma geral as rações utilizadas na alimentação de coelhos no Brasil, mesmo quando se utiliza alimentos regionais, seguem um padrão em que poderiam ser definidas como rações peletizadas completas, com as quais se suprem as exigências nutricionais da espécie. Dentre as varias categorias de alimentos que compõem as rações, os alimentos fibrosos são obrigatórios, pelo fato do coelho ser herbívoro e exigir um aporte mínimo de fibra na sua dieta. Esta exigência é a causa do preço mais elevado das rações, quando comparado a outras espécies, pelo fato dos alimentos fibrosos (fenos e subprodutos industriais) serem de custo elevado, se considerado seu valor nutritivo.

É importante também destacar, que na exploração de outras espécies animais, é possivel a redução de custos pela elaboração das rações nas propriedades, utilizando-se a mão-de-obra disponível e adquirindo a matéria prima a preços correntes de mercado.

Considerando-se que: a) as diferentes categorias de animais existentes numa criação de coelhos, são os animais em crescimento, aqueles responsáveis pelo maior consumo de alimento; b) o Brasil possui elevado potencial de produção de forragem e; c) que rações mais baratas podem ser obtidas se elaboradas nas propriedades, foi realizado este experimento com o objetivo de 
verificar os efeitos da utilização de concentrados com vários níveis de energia e proteína, nas formas farelada e peletizada, suplementadas diariamente com rami, sobre o desempenho de coelhos dos 35 aos 70 dias. 


\section{REVISÃO DA LITERATURA}

\subsection{Níveis de energia}

O nível de energia da ração é sem dúvida o fator preponderante no consumo de alimento, sendo os coelhos muito precisos em ajustar seus padrões de consumo rapidamente quando os níveis energéticos são mudados (Cheeke, 1987; Huang et al., 1989).

Neste sentido, Parigi-Bini (1968), trabalhando com 24 coelhos em crescimento de ambos os sexos, da raça Fulvo de Borgogna, alimentados à vontade com rações completas peletizadas isoprotéicas com $18,5 \%$ proteina bruta (PB) em média e com 4 níveis diferentes de energia líquida (EL) estimada $(1.518,1.618,1.727$ e $1.837 \mathrm{kcal} \mathrm{EL} / \mathrm{kg}$ de ração), encontrou que quanto maior o conteúdo energético da dieta menor o consumo de alimento por parte dos animais $(8.733 \mathrm{~g}, 7.543 \mathrm{~g}, 6.416 \mathrm{~g}$ e $5.780 \mathrm{~g}$ respectivamente para os niveis crescentes de energia), sendo a diferença significativa para os níveis extremos, com maior ganho de peso para as rações com menor teor energético. 
Trabalhando com rações contendo milho e farelo de gergelim na sua composição, com teores de energia digestível (ED) de 2.138, 2.552, 2.888, 2.911 e $3.072 \mathrm{kcal} / \mathrm{kg}$, Lebas (1975) avaliou o ganho de peso, o consumo de ração e a conversão alimentar em animais de ambos os sexos, tendo como resultados um menor consumo de alimento para as dietas com os maiores níveis de energia $(2.888 \mathrm{kcal} \mathrm{ED} / \mathrm{kg}=151 \mathrm{~g} / \mathrm{dia} ; 2.911 \mathrm{kcal} \mathrm{ED} / \mathrm{kg}=140 \mathrm{~g} /$ dia e para o nível $3.072 \mathrm{kcal} / \mathrm{kg}=144 \mathrm{~g} / \mathrm{dia}$ ), enquanto que para as rações contendo $2.138 \mathrm{kcal}$ $\mathrm{ED} / \mathrm{kg}$ e $2.552 \mathrm{kcal} \mathrm{ED} / \mathrm{kg}$ o consumo foi de $174 \mathrm{e} 170 \mathrm{~g} / \mathrm{dia}$ respectivamente. $\mathrm{O}$ mesmo ocorreu com a conversão alimentar $(4,37 ; 3,71 ; 3,25 ; 3,27$ e 3,23 respectivamente para os níveis $2.138,2.552,2.888,2.911$ e $3.072 \mathrm{kcal} \mathrm{ED/kg),}$ não havendo diferenças significativas para o ganho de peso diário.

Em experimento com animais em crescimento e níveis de energia na faixa entre 2.000 e $3.400 \mathrm{kcal} \mathrm{ED} / \mathrm{kg}$, Spreadbury \& Davidson citados por Cheeke $^{1}$ (1987) encontraram diminuição no consumo diário de ração a medida que era aumentado o teor energético da dieta. Também, Pote et al. citados por Cheeke $^{2}$ (1987), mediram o consumo diário de ração e avaliaram a conversão alimentar de animais em crescimento submetidos a dietas com niveis crescentes de energia, tendo observado a diminuição no consumo diário de ração e melhora na conversão alimentar a medida que se eleva o teor energético.

${ }^{1,2}$ CHEEKE, P. R. Rabbit feeding and nutrition. Orlando: Academic Press, 1987. $376 \mathrm{p}$. 
Butcher et al. (1983), alimentando animais da raça Califórnia desmamados aos 30 dias com dietas de baixa ou alta energia, mediram o ganho diário de peso, o consumo diário de ração e a conversão alimentar, encontrando maior ganho de peso para aqueles que foram alimentados com a dieta de alta energia do que aqueles alimentados com a dieta de baixa energia (31, 4 e 20,2 g/dia. O nível mais elevado de energia proporcionou menor consumo de ração $(116 \mathrm{~g} / \mathrm{dia})$ e melhor conversão alimentar $(1: 3,46)$ que o nível mais baixo $(133$ g/dia e 1:6.34, respectivamente).

Estudando o ganho de peso diário e a conversão alimentar em animais alimentados com rações contendo dois niveis de energia digestível (ED) e dois níveis de proteína digestível (PD), Maertens et al. (1989), utilizando rações com $2.045 \mathrm{kcal} \mathrm{ED} / \mathrm{kg}$ e 51,89 g PD/kcalED, $2.172 \mathrm{kcal} \mathrm{ED} / \mathrm{kg}$ e 59,84 g PD/kcalED, $2.458 \mathrm{kcal} \mathrm{ED} / \mathrm{kg}$ e $49,80 \mathrm{~g} \mathrm{PD} / \mathrm{kcalED}$ e $2.568 \mathrm{kcal} \mathrm{ED} / \mathrm{kg}$ e $59,01 \mathrm{~g}$ PD/kcalED, não encontraram diferenças significativas no ganho de peso diário para as quatro dietas $(39,1 ; 39,6 ; 41,3$ e $40,7 \mathrm{~g} /$ dia respectivamente). Enquanto que para a conversão alimentar não houve diferenças entre os níveis de proteína para um mesmo nivel de energia mas sim entre os níveis de energia (para $2.045 \mathrm{e}$ $2.172 \mathrm{kcal} \mathrm{ED} / \mathrm{kg}$ respectivamente de 3,86 e 3,77, e de 3,30 e 3,34 para os níveis de 2.458 e $2.568 \mathrm{kcal} \mathrm{ED} / \mathrm{kg})$.

Huang et al. (1989), avaliando os requerimentos de PB e ED num experimento fatorial com 3 níveis de energia $(2.350,2.500$ e $2.650 \mathrm{kcal} \mathrm{ED} / \mathrm{kg})$ e 
três níveis de $\mathrm{PB}(13,15$ e $17 \%$ ), observaram uma melhor conversão alimentar no nível $2.500 \mathrm{kcal} \mathrm{ED} / \mathrm{kg}$, ao mesmo tempo que para o nível de $15 \%$ de proteína bruta apresentou o maior consumo e o maior ganho de peso em relação aos outros grupos.

Comparando o desempenho de coelhos em crescimento, alimentados com rações contendo níveis alto, médio e baixo de energia e proteína, Shankhyan et al. (1990) concluíram ser a ração de alta energia e proteína a mais interessante, por apresentar o menor custo por $\mathrm{kg}$ de ganho de peso.

Utilizando coelhos mestiços (Nova Zelândia Branco x Califórnia), desmamados entre os 33 e os 35 dias, Castelló \& Gurri (1992) mediram o efeito de duas dietas de alta e baixa energia $(2.550$ e $2.400 \quad \mathrm{kcal} \quad \mathrm{ED} / \mathrm{kg}$ respectivamente) alimentados à vontade ou com restrição alimentar de 6 horas diárias, não encontrando grandes variações entre as dietas e o manejo alimentar para o ganho diário de peso, o consumo diário de ração e a conversão alimentar.

Num experimento com rações contendo cinco níveis de PB $(12,14,16$, 18 e $20 \%$ ) e dois níveis de ED (2.600 e $2.800 \mathrm{kcal} / \mathrm{kg}$ ), Scapinello et al. (1995) não encontraram diferenças significativas entre os niveis de energia para o ganho de peso e o consumo de ração, já para a conversão alimentar o nível $2.800 \mathrm{kcal}$ $\mathrm{ED} / \mathrm{kg}$ foi estatisticamente superior ao apresentado pelo nível $2.600 \mathrm{kcal} \mathrm{ED} / \mathrm{kg}$ $(2,95$ e 3,16 , respectivamente). 


\subsection{Níveis de proteína}

Para um ótimo crescimento, os coelhos dependem de quantidades adequadas de aminoácidos essenciais (NRC, 1977), e é na qualidade e na quantidade da proteína ingerida diariamente que se pode ter a certeza da nutrição adequada dos animais.

Com a finalidade de avaliar o efeito do nível protéico da ração sobre o desempenho de coelhos em crescimento, Lebas (1973a) realizou um experimento em três fases, inicialmente utilizando farelo de soja como principal fonte de proteína, testou cinco níveis $(11,14,17,20$ e $23 \%)$; ele verificou valores crescentes para o consumo diário de ração $(70,3 ; 80,7 ; 102,9 ; 106,4 ; 109,7 \mathrm{~g})$ e para $\circ$ ganho diário de peso $(20,1 ; 26,6 ; 34,2 ; 36,8 ; 38,4 \mathrm{~g})$ e melhora na conversão alimentar $(3,61 ; 3,40 ; 3,02 ; 2,91 ; 2,91)$ em função do aumento do teor de proteína da ração. As diferenças observadas foram significativas entre os níveis mais baixos (11 e $14 \%)$ e mais altos (17, 20 e $23 \%)$. Em uma segunda fase do mesmo experimento não houve diferenças entre as variáveis para os níveis de PB de $17,20,23,26$ e $29 \%$, ainda utilizando o farelo de soja como fonte de proteína. Já na terceira fase, com o farelo de gergelim como fonte de proteína, e níveis de $13,16,19,22$ e $25 \%$ de $P B$, não havendo diferenças entre os níveis 19,22 e $25 \%$ para consumo de ração e ganho de peso, sendo superiores 
aos níveis inferiores (13 e 16\%), enquanto não houve diferenças para a conversão alimentar.

Carregal \& Nikuma (1980), concluíram, num experimento utilizando coelhos de ambos os sexos da raça Nova Zelândia Branco desmamados aos 35 dias e submetidos a três rações que diferiam entre si no teor de $\mathrm{PB}(14,17$ e $20 \%$ ), que os níveis de proteína testados não afetaram o desempenho dos animais, apenas observando um pequeno efeito benéfico do aumento do teor protéico na dieta.

Para condições de clima tropical, Omole (1980) avaliou o efeito de cinco níveis de $\mathrm{PB}$ na dieta $(10,14,18,22$ e $26 \%)$ em rações à base de milho, torta de amendoim, farinha de peixe e óleo de dendê sobre o ganho de peso diário (GPD), consumo diário de ração (CDR) e a conversã்o alimentar (CA) de coelhos em crescimento da raça Nova Zelândia Branco, tendo encontrado como nível ótimo de $\mathrm{PB}$ o de $18 \%(\mathrm{GPD}=25,8 \mathrm{~g} ; \mathrm{CDR}=88,8 \mathrm{~g}$ e $\mathrm{CA}=3,44)$.

Abdella et al. (1988) trabalharam com três níveis de proteína $(16,18$ e $20 \%$ ) avaliaram o ganho de peso, o consumo de ração, a conversão alimentar e o rendimento de carcaça, tendo encontrado que na dieta com $16 \%$ de $\mathrm{PB}$ o melhor ganho diário de peso $(27,71 \mathrm{~g})$ e o melhor rendimento de carcaça $(50,21 \%)$, enquanto que as dietas com 18 e $20 \%$ de proteína bruta apresentaram ganhos de 26,77 e $27,22 \mathrm{~g}$ e rendimento de carcaça de 48,90 e $49,23 \%$ respectivamente, mas não sendo observada grandes diferenças entre as dietas. Já a dieta contendo $18 \%$ 
de proteína apresentou um menor consumo de ração $(106,2 \mathrm{~g})$ e uma melhor conversão alimentar $(3,97)$, sendo os valores para as outras dietas de $116,2 \mathrm{~g}$ de ração por dia e uma conversão alimentar de 4,20 para a dieta com $16 \%$ de proteína e $119,9 \mathrm{~g}$ e 4,40 para a dieta com nível de $20 \%$.

Com rações à base de milho, farelo de soja e alfafa e três níveis de PB (20, 23 e 26\%), Coan et al. (1988) verificaram após o fornecimento das rações para as fêmeas e posterior fornecimento às respectivas ninhadas, desmamadas às cinco semanas, que não houve diferenças entre os tratamentos para o consumo de alimento, a conversão alimentar, o ganho de peso e a idade de abate.

Ayyat (1991), utilizando rações com 14,35 e 16,4\% de proteína bruta, suplementadas com três níveis de metionina ou não, observou que para coelhos da raça Nova Zelândia Branco e para o nível zero de suplementação de metionina $(0,55 \%$ de metionina+cistina na dieta), a ração com maior teor de proteína apresentou um ganho de peso diário de $24,2 \mathrm{~g}$ enquanto que para a de menor teor protéico foi de 18,7, e uma conversão alimentar também melhor 3,93 e 5,42 para os níveis maior e menor de proteína bruta respectivamente.

Alimentando coelhos de ambos os sexos com rações contendo níveis crescentes de PB (15; 17,5 e 20\%), Sonbol et al. (1992) concluíram que há uma melhoria significativa na conversão alimentar a medida que há um incremento no nível de proteína bruta da dieta. 
Utilizando rações completas fareladas e coelhos em crescimento da raça Nova Zelândia Branco, Toledo et al. (1994) avaliaram três níveis de PB (14, 16 e $18 \%$ ), sendo que para o ganho de peso e a conversão alimentar os níveis 16 e $18 \%$ não diferiram entre si $(22,42$ e $23,23 \mathrm{~g}$ e 4,72 e 4,63 respectivamente) mas sim do nível $14 \%(21,71$ e 4,88$)$.

\subsection{Forma física da ração}

Outro fator que afeta o consumo de alimento por parte dos coelhos é a forma física da ração (Cheeke, 1987). Segundo Wang et al. (1984), animais alimentados com rações na forma peletizada, apresentam altas taxas de sobrevivência nos períodos de pré e pós desmama, além de rápido ganho de peso.

Coelhos não toleram pó e por isso é preferível o uso de dietas peletizadas (Lebas, 1988), apesar de ainda hoje existirem regiões no mundo, para as quais se torna inviável o uso de rações peletizadas devido ao seu custo e o sistema de criação adotado.

O uso de alimento farelado pode ocasionar desperdício de ração devido à seleção por parte do coelho (Owen, 1981).

Lebas (1973b), utilizando duas rações à base de milho integral ou amido de milho e farelo de soja, cada uma delas nas formas farelada e granulada, avaliou o ganho de peso, o consumo de ração e a conversão alimentar de coelhos 
em crescimento, sendo que para os três parâmetros, e em ambas as dietas, os coelhos alimentados com as rações na forma granulada $(29,4 ; 87,4$ e 3,36 para a dieta $\mathrm{A}$ e 36,$0 ; 105,8$ e 2,95 para a dieta B) tiveram melhor desempenho que aqueles alimentados com as rações fareladas $(26,7 ; 97,7$ e 4,29 para a dieta A e $29,7 ; 91,7$ e 3,12 para a dieta $B)$.

Estudando o efeito da forma física da dieta sobre o desempenho de coelhos em crescimento, King et al. citado por Cheeke ${ }^{3}$ (1987), avaliou o ganho diário de peso (GDP), o consumo diário de ração (CDR) e a conversão alimentar, tendo encontrado os valores 22,9 e $20,7 \mathrm{~g}$ para o GDP, 85 e $79 \mathrm{~g}$ para o CDR e 3,8 e 3,7 para a CA nas rações peletizadas e fareladas respectivamente.

Machin et al. (1980), reproduzindo condições tropicais e utilizando rações completas em três formas físicas (peletizada, farelada e farelada úmida com $40 \%$ de água) e dois níveis de energia (1.900 e $2.860 \mathrm{kcal} \mathrm{ED} / \mathrm{kg})$, estudaram o tempo para atingir os $2 \mathrm{~kg}$ de peso vivo, o ganho de peso, o consumo de ração, a conversão alimentar e o rendimento de carcaça. Para todos os parâmetros estudados as rações com maior nível de energia foram superiores a aquelas com menor nível. Para o nível de $2.800 \mathrm{kcal} \mathrm{ED/kg}$, a ração peletizada apresentou melhores resultados que a ração farelada úmida e a farelada seca

${ }^{3}$ CHEEKE, P. R. Rabbit feeding and nutrition. Orlando: Academic Press, 1987. 376p. 
quanto ao consumo $(104,78$ e $102 \mathrm{~g} / \mathrm{dia})$, ganho diário de peso $(33,1 ; 26,5$ e $27,9 \mathrm{~g})$ e tempo necessário para atingir $2,0 \mathrm{~kg}$ de peso vivo $(71,76$ e 78 dias $) . \mathrm{O}$ rendimento de carcaça, entretanto, foi maior para farelada seca $(63,14 \%)$ e farelada úmida $(61,04 \%)$ em relação a peletizada $(59,08 \%)$.

Trabalhando com rações fareladas e peletizadas Harris et al. (1983) estudaram o desempenho (ganho de peso e conversão alimentar) e a mortalidade de coelhos em crescimento, tendo encontrado para animais os alimentados com dietas peletizadas, ganho de peso diário $(43 \mathrm{~g})$ e a conversão alimentar $(3,16)$ superiores a aqueles encontrados nas rações fareladas $(29,3 \mathrm{~g}$ e 6,14 para ganho de peso e conversão alimentar). A taxa de mortalidade foi a mesma para ambas as rações. Os autores mediram tambẻm as preferências alimentares dos animais mediante o fornecimento das duas rações ao mesmo grupo em comedouros diferentes, sendo o consumo total de ração peletizada de $68,8 \mathrm{~kg}(97,4 \%$ do total), enquanto que para a farelada foram consumidos apenas $1,83 \mathrm{~kg}(2,6 \%)$.

Utilizando 2 formas físicas da ração (peletizada e farelada) e analisando o ganho de peso $(33,7$ e $21,7 \mathrm{~g} /$ dia respectivamente para as rações peletizada e farelada), o consumo diário de ração (92 e 177g/dia) e a conversão alimentar $(2,73$ e 8,16$)$, Sanchez et al. (1984) concluíram que a ração peletizada forneceu um melhor desempenho, tendo atribuido o alto consumo de ração e a alta conversão alimentar da ração farelada ao elevado desperdiço por parte dos animais. No mesmo experimento trabalhando com uma ração peletizada exclusiva 
e uma dieta combinada (1 farelada: 1 peletizada), observaram que para a dieta combinada houve um consumo maior de alimento $(128,8 \mathrm{~g}$ por dia) em relação aos $126,8 \mathrm{~g}$ /dia para a dieta com a ração peletizada exclusiva, e um melhor ganho de peso diário $(47,1 \mathrm{~g} / \mathrm{dia})$ e conversão alimentar $(2,8)$ do que aqueles apresentados pela ração peletizada $(41,1 \mathrm{~g} / \mathrm{dia}$ e 3,1$)$.

Dietas umedecidas com 30 ou $60 \%$ de água ou peletizadas foram fornecidas a coelhos de 48 dias de idade por Lee \& Huang (1984), sendo que aqueles alimentados com rações peletizadas sem adição de água apresentaram o melhor ganho com $32 \mathrm{~g} /$ dia e uma melhor conversão alimentar com 3,2 , enquanto que aqueles alimentados com a ração misturada com $30 \%$ de água, apresentaram os piores valores para ganho de peso diário $(20 \mathrm{~g})$ e conversão alimentar $(4,4)$.

El-Hindawy et al. (1992) trabalhando com uma ração contendo $16,24 \%$ de proteína bruta e $2.720 \mathrm{kcal} \mathrm{ED} / \mathrm{kg}$ peletizada e farelada, concluíram que os animais alimentados com a ração peletizada mostraram um maior ganho de peso, um menor consumo de ração e uma menor mortalidade.

Farinu (1994) comparou o desempenho de coelhos mestiços quando alimentados com ração formulada a base de alimentos não convencionais (18\% PB, $15,8 \%$ de fibra bruta e $2.985 \mathrm{kcal}$ ED $/ \mathrm{kg})$, ração peletizada completa $(17,5 \%$ PB, $10,7 \%$ de fibra bruta e $2.650 \mathrm{kcal} \mathrm{ED} / \mathrm{kg})$ e ração farelada de aves $(15,4 \%$ $\mathrm{PB}, 8,7 \%$ de fibra bruta e $2.475 \mathrm{kcal} \mathrm{ED} / \mathrm{kg}$ ). Constatou que os animais tiveram melhor desempenho com a dieta não convencional $(15,2 \mathrm{~g} /$ dia de ganho de peso), 
em virtude dos valores para as dietas peletizada e de aves serem 13,4 e 6,3g/dia de ganho de peso.

\subsection{Uso de rações concentradas}

$\mathrm{Na}$ prática da criação racional e comercial de coelhos o sistema de alimentação mais utilizado é o fornecimento de uma ração completa, ou seja, ração que contém frações energéticas, protéicas e fibrosas em uma mesma mistura, alem de suplementos vitamínicos e minerais, seja peletizada ou farelada.

É conhecido que a fração fibrosa em uma ração completa desempenha funções importantes na nutrição de coelhos, como por exemplo na prevenção de enterites, no crescimento e na prevenção na formação de bolas de pêlos no estômago dos coelhos (Cheeke et al., 1986). Também é conhecido que a diminuição da fração fibrosa acarreta aumento no teor energético da dieta.

Num experimento realizado por Parigi-Bini \& Chiericato (1974) utilizando animais mestiços (NZBxCAL) divididos em dois grupos de oito animais cada um, os quais foram alimentados com duas dietas com diferentes teores de fibra bruta, uma com alto teor de fibra $(11,08 \%)$ e outra com baixo teor de fibra $(4,49 \%)$, obtiveram melhores resultados para o ganho de peso vivo e conversão alimentar com a ração de baixa fibra $(41,4 \mathrm{~g} /$ dia e 2,28$)$ do que aqueles obtidos para a ração com nível de fibra adequado $(35,3 \mathrm{~g} /$ dia e 2,81$)$. 
Para o consumo diário de ração não foram encontradas diferenças significativas, tendo sido de 84,5 e $90,6 \mathrm{~g} /$ dia para as dietas com baixo teor e com alto teor de fibra, respectivamente.

Num experimento em Trinidad realizado por Rastogi (1986), animais desmamados aos 28 dias de idade receberam uma ração peletizada para frangos em terminação, alta em energia e pobre em fibra (18\% de proteína bruta, $2,5 \%$ de gordura e $4,5 \%$ de fibra bruta), sendo fixada em um tratamento e em quantidades crescentes com a idade nos demais, suplementada com gramíneas de diversas espécies. $O$ autor obteve valores de eficiência alimentar semelhantes aos encontrados em experimentos feitos tanto em condições de clima tropical como temperado, sendo que nesses experimentos a rações, ao contrario das utilizadas neste caso, tinham elevado teor de fibra e baixo teor energético.

Esse tipo de manejo alimentar, utilizando uma fonte de alimento concentrado, pode se corretamente chamado de alimentação dissociada. E foi nessa linha que Ruffini-Castrovilli \& Rigoni (1983), forneceram a coelhos em crescimento uma ração concentrada de $25 \%$ de PB e $6,9 \%$ de fibra bruta (FB), e feno cuja composição era de $12 \%$ de PB e $28,8 \%$ de FB. Os alimentos foram fornecidos em três esquemas diferentes: o primeiro fornecendo o alimento concentrado no período da manhã e o feno no período da tarde $(\mathrm{C}+\mathrm{F})$, o segundo o inverso do primeiro, feno no período da manhã e concentrado no período da tarde $(\mathrm{F}+\mathrm{C})$, e o terceiro sendo uma mistura de partes iguais de feno e 
concentrado (1:1), cuja composição química era de 19\% PB e $17 \%$ FB. Foram avaliados o ganho de peso, o consumo de concentrado e o consumo de feno, e o tratamento $\mathrm{C}+\mathrm{F}$ foi o que proporcionou um maior ganho de peso para os animais $(43,0 \mathrm{~g} / \mathrm{dia})$ em relação aos outros tratamentos $(\mathrm{F}+\mathrm{C}=36,7 \mathrm{~g} /$ dia e $1: 1=38,3$ g/dia). O consumo de alimento concentrado e de feno para os tratamentos $C+F$, $\mathrm{F}+\mathrm{C}$ e $1: 1$ foram de 58,2 e $16,6 \mathrm{~g} / \mathrm{dia}, 59,5$ e $21,3 \mathrm{~g} / \mathrm{dia}$ e 51,0 e $51,0 \mathrm{~g} / \mathrm{dia}$ respectivamente, mostrando um menor consumo para o tratamento com maior ganho, e uma melhor conversão alimentar.

Poismans \& Wittouk (1986), utilizando duas dietas experimentais à base de farelo e soja e palha de trigo, contendo a dieta A $18,9 \%$ de PB, $20,2 \%$ de FB e $2.414 \mathrm{Kcal} \mathrm{ED} / \mathrm{kg}$ e a dieta B $27 \%$ de $\mathrm{PB}, 12,4 \%$ de FB e $2.783 \mathrm{kcal} \mathrm{ED} / \mathrm{kg}$, observaram um melhor desempenho da dieta B com um ganho de peso diário de $35 \mathrm{~g}$ e uma conversão alimentar de 3,22 , superior a aqueles valores apresentados pela dieta B (29g para ganho diário de peso e uma conversão alimentar de 3,78$)$.

Tendo o farelo de soja e milho como alimentos básicos, acrescidos de farelo de milho e dois subprodutos da mandioca, Onifade \& Tewe (1993) formularam quatro rações com diferentes percentagens de FB : 5,50;6,94; 9,10 e 11,18. A ração contendo $9,10 \%$ de FB proporcionou o maior ganho de peso e a de $11,8 \%$ o menor, além da pior conversão alimentar. $O$ consumo diário foi maior com as rações mais altas em fibra. 
Blas et al. (1994), alimentando dois grupos de 600 coelhos cada um, desmamados aos 28 dias, com duas dietas (A e B) contendo 15,3 e $11,6 \%$ de fibra bruta, teores de amido de 16,4 e $24,8 \%$, proteína bruta de 16,2 e $17 \%$ e níveis de energia de 9,7 e 10,9 $\mathrm{MJ}$ ED/kg respectivamente, não observaram diferenças para o ganho de peso $(37,7 \mathrm{~g} / \mathrm{dia})$, tendo apenas um menor consumo diário de ração para a dieta $\mathrm{B}(84,5 \mathrm{~g})$ do que aquele da dieta $\mathrm{A}(95,5 \mathrm{~g})$ e uma melhor conversão alimentar na dieta $\mathrm{B}$ em relação à dieta $\mathrm{A}(2,27$ e 2,55).

\subsection{Alimento Volumoso}

\subsubsection{Uso de Forragens como alimento suplementar}

Ao se pensar em suplementação do alimento concentrado com alimento volumoso, deve-se levar em consideração o consumo voluntário destes alimentos por parte dos animais. E assim, trabalhando com cevada, aveia, uma mistura de aveia e cevada, milho e feno de alfafa, Sanchez et al. citados por Cheeke ${ }^{4}$ (1987) verificaram que quando fornecido à vontade o grão moído e feno de alfafa, os animais ingeriram 60 a $70 \%$ de grão e 30 a $40 \%$ de feno proporcionando um desempenho semelhante para os diversos grão utilizados, o que sugere que ocorre um balanceamento da ração por parte dos animais.

${ }^{4}$ CHEEKE, P. R. Rabbit feeding and nutrition. Orlando: Academic Press, 1987. 376p. 
Uma das vantagens da produção de coelhos em paises tropicais pode ser o uso de forragens e subprodutos não utilizados para o consumo humano, sendo a quantidade de forragem a ser utilizada próxima à quantidade de consumo voluntário (Lukefahr \& Cheeke, 1991). Os autores ainda citam que o fornecimento de alimentos volumosos frescos pode ser realizado duas vezes ao dia, tomando-se o cuidado de retirar o material remanescente por ocasião da nova distribuição, podendo-se suplementar com aproximadamente $50 \mathrm{~g}$ de alimento concentrado, o qual pode ser comercial ou elaborado pelo criador.

Carregal et al. (1982) em experimento com coelhos em crescimento durante um período de 25 dias, avaliaram três dietas: ração comercial exclusiva, ração comercial mais suplementação com capim elefante e a terceira, capim elefante como alimento exclusivo. O tratamento onde a ração comercial completa era suplementada com capim elefante apresentou um maior ganho de peso $(40,8$ $\mathrm{g} / \mathrm{dia})$ associada a um maior consumo de alimento $(135,34 \mathrm{~g} / \mathrm{dia})$ e a uma menor conversão alimentar $(2,84)$, já aos menores valores de ganho de peso, consumo diário de ração e conversão alimentar foram obtidos com a dieta de capim elefante $(14,6 \mathrm{~g} / \mathrm{dia} ; 30,14 \mathrm{~g}$ e 2,08$)$.

Estudando o efeito do fornecimento de alimento volumoso à vontade, volumoso mais 25,50 e $75 \mathrm{~g}$ de ração peletizada completa, volumoso e a ração peletizada à vontade ou apenas a ração peletizada à vontade, Pote et al. citado 


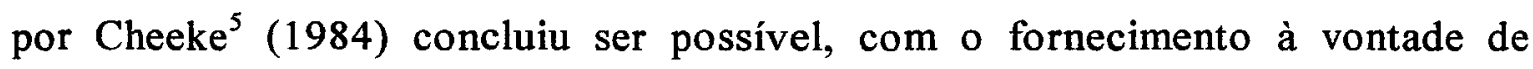
alimento volumoso, reduzir o consumo de alimento concentrado praticamente à metade (para a dieta de volumoso mais $75 \mathrm{~g}$ de concentrado) em relação a aquele obtido com a dieta de alimento concentrado (127 e 66,6 g/dia) sem alterar a resposta em ganho de peso $(37,2 \mathrm{~g} /$ dia para a dieta suplementada e $36,8 \mathrm{~g} / \mathrm{dia}$ para a dieta de concentrado exclusivo).

Alimentando 60 coelhos mestiços em crescimento com 4 dietas (T1 ração básica; T2 - ração básica + capim angola à vontade; T3 - 75\% ração + capim angola à vontade e T4 - 50\% ração + capim angola à vontade) durante 35 dias não foram observadas diferenças significativas para ganho de peso entre os tratamentos $\mathrm{T} 1$, T2 e T3, diferindo apenas o tratamento com $50 \%$ da ração básica (Crespi et al., 1984a).

Harris et al. (1984) estudaram a suplementação de uma ração peletizada completa com feno de gramíneas e feno de alfafa, encontrando que para o ganho de peso a substituição com feno de alfafa $(40,9 \mathrm{~g} /$ dia $)$ e feno de gramínea $(38,2$ g/dia) foi superior ao ganho obtido com a ração peletizada exclusiva $(36,4 \mathrm{~g} / \mathrm{dia})$. Ainda, quando a ração foi suplementada, houve um menor consumo de ração peletizada e uma melhor conversão alimentar .

${ }^{5}$ CHEEKE, P. R.. Rabbit nutrition and feeding: recent advances and future perspectives. Journal of Applied Rabbit Research, v.7, n.1, p.31-37, Jan./Mar. 1984. 
Utilizando folhas de amoreira (Morus alba) Crespi et al. (1986) alimentaram coelhos em crescimento com uma ração balanceada (RB), e três níveis de substituição da ração balanceada por folhas de amoreira (10, 20 e 30\%), não tendo encontrado diferenças entre os tratamentos para o ganho de peso e rendimento de carcaça. Para o consumo diário de forragem foi observado um aumento do consumo de folha de amoreira a medida que se reduzia a quantidade de ração balanceada, contribuindo assim para o aumento do consumo de total de alimento e da conversão alimentar.

Raharjo et al. (1988), avaliaram o desempenho de coelhos com idade entre 5 e 10 semanas alimentados com nove forrageiras tropicais, mais ração balanceada à vontade ou em quantidades crescentes para cada semana de idade (40 a $55 \mathrm{~g} /$ dia entre a $6^{a}$ e $10^{a}$ semana). O melhor desempenho foi obtido com os coelhos alimentados com ração balanceada à vontade $(23,8 \mathrm{~g} / \mathrm{dia}$ de ganho de peso) enquanto que o melhor resultado, usando forragem, foi aquele onde se empregou leucena (ganho de peso de 14,1 g/dia), seguido de Sesbania spp., folhas de mandioca e folhas de mamoeiro $(12,7 ; 12,3$ e $10,7 \mathrm{~g}$ por dia respectivamente), sendo o pior tratamento aquele onde a braquiária foi utilizada $(2,6 \mathrm{~g})$.

Utilizando animais das raças Nova Zelândia Branco, Califórnia e Kenya Branco, alimentados com três niveis de alimento concentrado (baixo $=50 \mathrm{~g} / \mathrm{dia}$; médio $=75 \mathrm{~g} /$ dia e alto $=100 \mathrm{~g} / \mathrm{dia})$ suplementados com feno de capim de rhodes, 
folhas de milho e ramas de batata doce, Mutetikka et al. (1990) estudaram o ganho de peso dos animais, verificando para o capim de rhodes um maior ganho de peso quando utilizado o nível alto de concentrado $(21,23 \mathrm{~g} / \mathrm{dia})$ do que aquele obtido com os níveis médio e baixo (15,69 e 8,7 g/dia respectivamente). Os alimentados com folhas de milho apresentaram melhor desempenho, comparado com o feno de rhodes e os valores fora de $23,54 \mathrm{~g} /$ dia para o nível alto, $20,04 \mathrm{~g}$ para o nível médio e 13,06g para o nível baixo. Quando a ração foi suplementada com ramas de batata doce, os animais apresentaram o melhor desempenho $(26,3$; 23,73 e 20,94 g/dia para alto, médio e baixo nível de concentrado).

El-Kerdawy et al. (1992) alimentaram coelhos em crescimento, desmamados aos 28 dias de idade com ração completa e folhas secas de cenoura, em níveis de 0, 20, 40 e $60 \%$ da dieta. Observaram para o ganho diário de peso valores de 24,$9 ; 23,4 ; 21,7$ e 22,1 g para cada um dos níveis de substituição e valores de 3,$69 ; 3,66 ; 3,63$ e 3,01 para a conversão alimentar.

\subsubsection{Uso do rami (Bohemeria nivea)}

O rami é dentre as plantas forrageiras utilizadas na cunicultura, uma das mais promissoras para utilização, tanto na forma de feno (sendo um material fibroso, de aspecto grosseiro que pode dificultar a mistura com os concentrados. Zinsly, 1970) como na forma de alimento volumoso fresco, devido à sua 
composição química bromatológica. Como forragem verde apresenta, $82,65 \%$ de água, 4,3\% de $\mathrm{PB}, 2,4 \%$ de $\mathrm{FB}, 0,6 \%$ de extrato etéreo, $0,74 \%$ de cálcio e $0,05 \%$ de fósforo, e na forma de feno, $24,8 \%$ de PB, $13,51 \%$ de FB, $4,25 \%$ de cálcio e 0,28\% de fósforo (Echeverri, 1960). Segundo Nascimento (1993) a composição química do rami na forma de feno é de $89,45 \%$ de matéria seca, $20,05 \%$ de proteína bruta, $22,01 \%$ de fibra bruta, $4,06 \%$ de cálcio e $0,40 \%$ de fósforo.

Cordoba (1961), recomenda o corte, quando as plantas atingem uma altura aproximada de $50 \mathrm{~cm}$. $O$ autor cita que na Guatemala os cortes eram realizados aos 22 ou 15 dias dependendo das condições climáticas e de altitude e ainda faz menção ao fato das plantas, quanto mais tenras, possuírem maior percentagem de proteína.

Trabalhando com feno de rami como componente de rações fareladas isoprotéicas e coelhos da raça Norfolk, Mendes et al. (1980) testaram a inclusão de 25 e $50 \%$ de feno de rami nas rações em substituição às outras fontes de fibra utilizadas, e encontraram que para o ganho de peso diário (GPD), o consumo diário de ração (CDR), a conversão alimentar (CA) e o rendimento de carcaça (RC) não houve diferenças significativas entre a ração balanceada sem substituição e aquela com $25 \%$ de feno de rami, como mostram os valores para cada um destes tratamentos $\mathrm{GPD}=22,39$ e $22,1 \mathrm{~g}, \mathrm{CDR}=93,3$ e $95,9 \mathrm{~g}, \mathrm{CA}=$ 4,4 e 4,3 e $\mathrm{RC}=52,9$ e 53,2 \%. Para o tratamento onde houve inclusão de $50 \%$ 
de feno de rami os resultados foram $6,5 \mathrm{~g}, 47,3 \mathrm{~g}, 8,7$ e 45,1\% para GDP, CDR, CA e $R C$ respectivamente.

Crespi et al. (1984b) utilizando coelhos da raça Nova Zelândia Branco na fase de crescimento, durante um período experimental de 31 dias, utilizando ração balanceada sem restrição ou com restrição de 20,40 ou $60 \%$ e suplementação com rami, concluíram que a restrição de $40 \%$ da ração balanceada suplementada com rami à vontade, foi viável economicamente. Os resultados quanto ao desempenho foram os seguintes para os níveis $0,20,40$ e 60 de substituição respectivamente: 36,$89 ; 36,57 ; 35,08$ e $31,61 \mathrm{~g}$ para ganho diário de peso, 0,$0 ; 175,4 ; 218,1$ e $321,4 \mathrm{~g}$ para consumo diário de rami, 123,$0 ; 125,2$; 118,13 e $113,7 \mathrm{~g}$ para o consumo diário de ração, 3,$88 ; 3,97 ; 3,92$ e 4,18 para a conversão alimentar e 62,$96 ; 62,8 ; 62,76$ e $61,22 \%$ para o rendimento de carcaça. 


\section{MATERIAL E MÉTODOS}

\subsection{Generalidades}

O experimento foi conduzido no Setor de Cunicultura do Departamento de Zootecnia da Escola Superior de Agricultura "Luiz de Queiroz " - Piracicaba, Estado de São Paulo, no período de 2 de julho a 16 de agosto de 1996.

Foram utilizados 120 animais de ambos os sexos, sendo 72 animais puros da raça Nova Zelândia Branco (NZB) e 48 animais mestiços das raças Nova Zelândia Branco e Califórnia (NZBxCAL), desmamados aos 35 dias de idade.

Os animais foram alojados individualmente, em gaiolas de arame galvanizado com $40 \mathrm{~cm}$ de largura, $60 \mathrm{~cm}$ de profundidade $\mathrm{e} 30 \mathrm{~cm}$ de altura, fornecendo uma área de alojamento de $0,24 \mathrm{~m}^{2}$ (densidade $=4,2$ animais $/ \mathrm{m}^{2}$ ).

Cada gaiola foi equipada com comedouro automático, tipo túnel, (Figura 1) e bebedouro automático.

Para escolha dos animais utilizados no experimento, todos eles foram pesados na desmama e identificados através de tatuagem na orelha, tendo sido 
Figura 1. Comedouro automático tipo tunel.
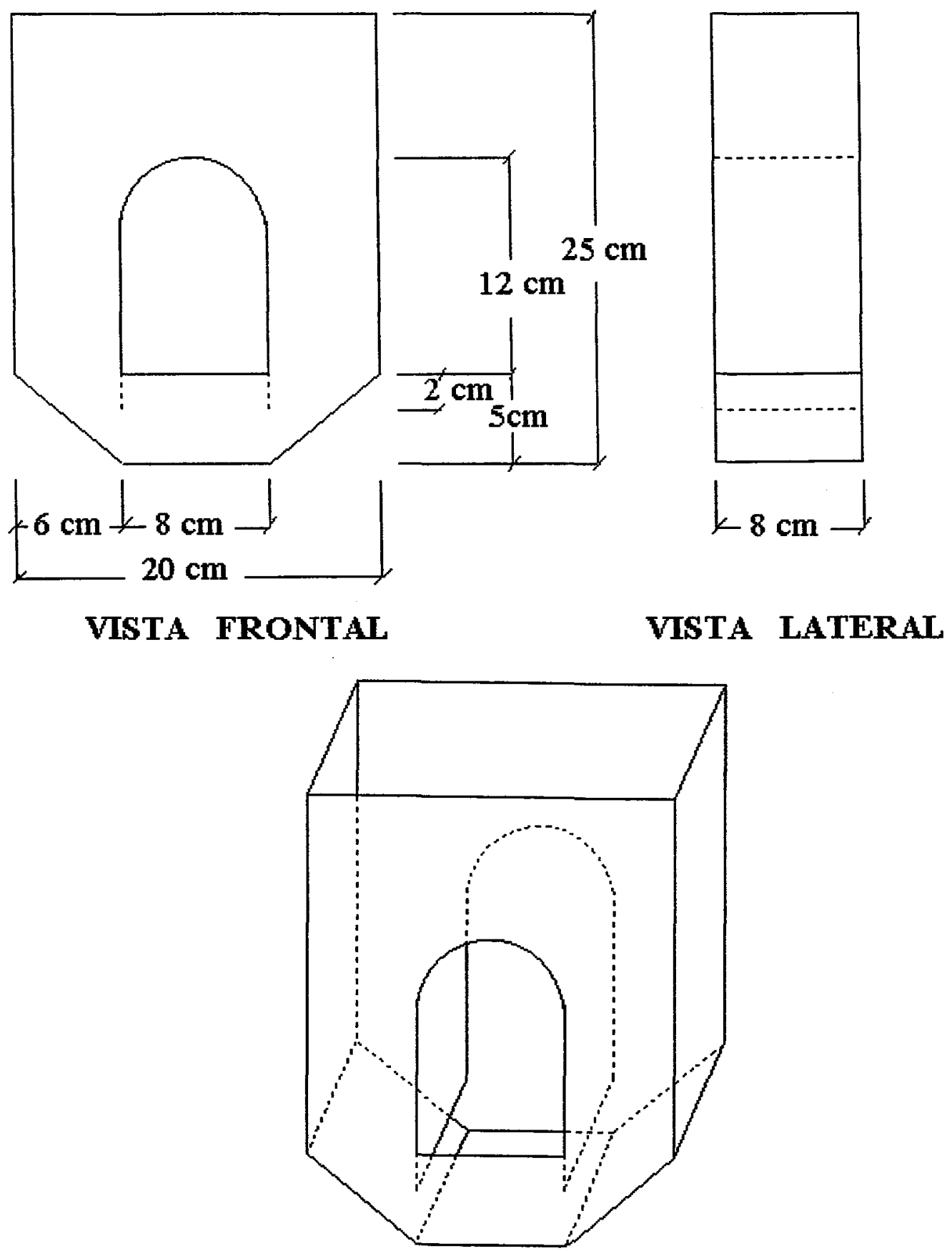

VISTA EM PROFUNDDADE 
eliminados os animais com pesos extremos; os demais foram agrupados por peso para a formação dos blocos.

Os coelhos foram pesados semanalmente até os 70 dias de idade.

\subsection{Alimentação dos Animais}

Os animais receberam concentrado à vontade, sendo o consumo medido uma vez por semana por ocasião da pesagem dos animais.

O rami foi cortado e fornecido diariamente no periodo da tarde em quantidade aproximada de $80 \mathrm{~g}$ de matéria verde, por animal.

\subsection{Tratamentos}

Foram estudados 12 tratamentos referentes a utilização de três níveis de energia $(2700,3000$ e $3300 \mathrm{kcalED} / \mathrm{kg})$, dois níveis de proteína (16 e $20 \%$ PB) e duas formas física do concentrado (farelado e peletizado).

Os tratamentos foram os seguintes:

$\mathrm{T} 1 \mathrm{~F}=$ Concentrado com $2700 \mathrm{kcalED} / \mathrm{kg}, 16 \% \mathrm{~PB}$ farelado

$\mathrm{T} 2 \mathrm{~F}=$ Concentrado com $3000 \mathrm{kcalED} / \mathrm{kg}, 16 \% \mathrm{~PB}$ farelado.

$\mathrm{T} 3 \mathrm{~F}=$ Concentrado com $3300 \mathrm{kcalED} / \mathrm{kg}, 16 \% \mathrm{~PB}$ farelado. 
$\mathrm{T} 4 \mathrm{~F}=$ Concentrado com $2700 \mathrm{kcalED} / \mathrm{kg}, 20 \% \mathrm{~PB}$ farelado

$\mathrm{T} 5 \mathrm{~F}=$ Concentrado com $3000 \mathrm{kcalED} / \mathrm{kg}, 20 \% \mathrm{~PB}$ farelado

$\mathrm{T} 6 \mathrm{~F}=$ Concentrado com $3300 \mathrm{kcalED} / \mathrm{kg}, 20 \% \mathrm{~PB}$ farelado.

$\mathrm{T} 1 \mathrm{P}=$ Concentrado com $2700 \mathrm{kcalED} / \mathrm{kg}, 16 \% \mathrm{~PB}$ peletizado

$\mathrm{T} 2 \mathrm{P}=$ Concentrado com $3000 \mathrm{kcalED} / \mathrm{kg}, 16 \% \mathrm{~PB}$ peletizado.

$\mathrm{T} 3 \mathrm{P}=$ Concentrado com $3300 \mathrm{kcalED} / \mathrm{kg}, 16 \% \mathrm{~PB}$ peletizado

$\mathrm{T} 4 \mathrm{P}=$ Concentrado com $2700 \mathrm{kcalED} / \mathrm{kg}, 20 \% \mathrm{~PB}$ peletizado

$\mathrm{T} 5 \mathrm{P}=$ Concentrado com $3000 \mathrm{kcalED} / \mathrm{kg}, 20 \% \mathrm{~PB}$ peletizado

$\mathrm{T} 6 \mathrm{P}=$ Concentrado com $3300 \mathrm{kcalED} / \mathrm{kg}, 20 \% \mathrm{~PB}$ peletizado

\subsection{Rações experimentais}

Com base na composição química bromatológica dos ingredientes foram formuladas e preparadas as rações experimentais. As análises foram realizadas no Laboratório de Bromatologia do departamento de Zootecnia da Escola Superior de Agricultura " Luiz de Queiroz ". Os resultados das análises são apresentados na Tabela 1.

A composição percentual e a composição química bromatológica dos concentrados se encontram nas Tabelas 2 e 3 respectivamente. 


\subsection{Variáveis estudadas}

Foram objeto de estudo as seguintes variáveis: ganho diário de peso (GDP), consumo diário de concentrado (CDC) e conversão alimentar dos concentrados (CAC).

\subsection{Delineamento Experimental}

Utilizou-se um delineamento experimental em blocos casualizados com esquema fatorial $3 \times 2 \times 2$, para estudar os efeitos dos níveis de energia, níveis de proteína e forma fisica da concentrado sobre o desempenho dos animais.

Cada tratamento teve dez repetições de um animal, tendo sido a unidade experimental representada por uma gaiola.

\subsection{Custo dos concentrados experimentais}

Com o intuito de comparar o custo do alimento concentrado por kilo vivo de coelho produzido, foi calculado o custo dos concentrados experimentais segundo duas fontes de preços de matéria prima. Os respectivos valores são mostrados na Tabela 4. 


\subsection{Análise Estatística}

As análises das variâncias foram obtidas utilizando-se o PROC GLM do SAS (1987) e para a comparação das médias foi utilizadio o teste SNK (StudentNewman-Keuls).

Os efeitos dos níveis de energia foram decompostos através dos polinômios ortogonais em componentes de regressão linear e quadrática.

Foi efetuado também o teste do chi-quadrado para verificar diferenças significativas entre a mortalidade ocorrida dentro de cada tratamento. 


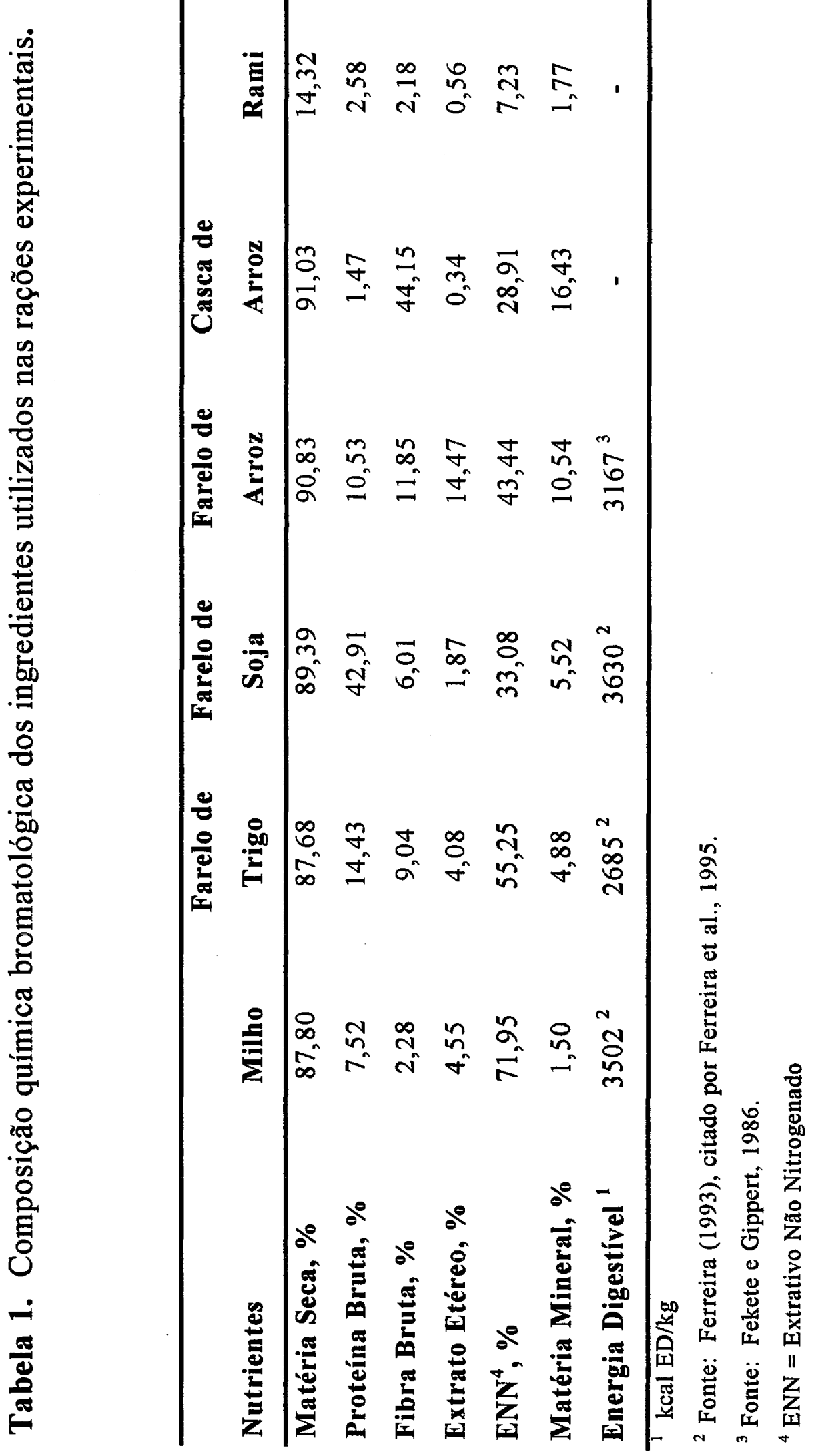


告

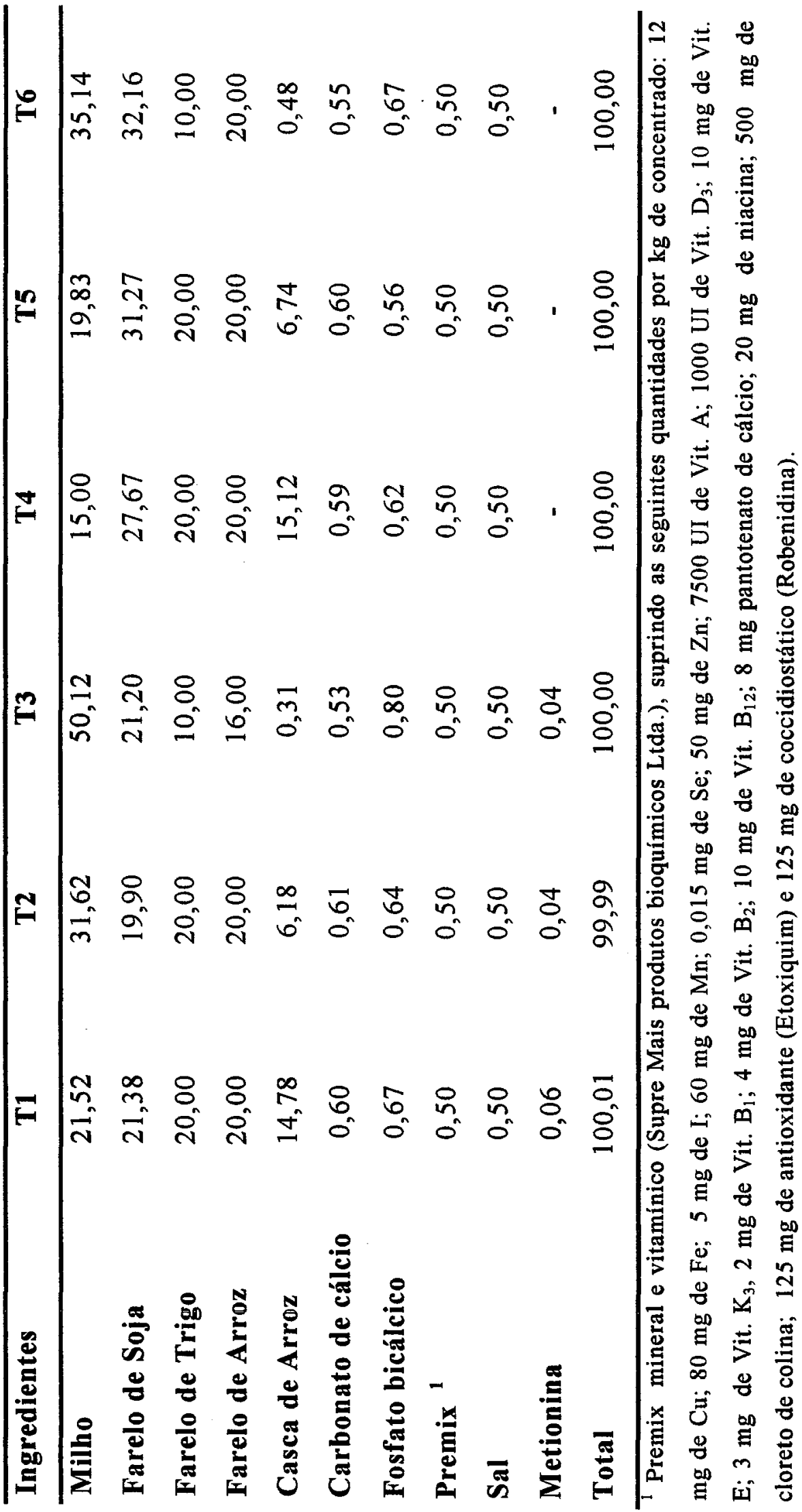




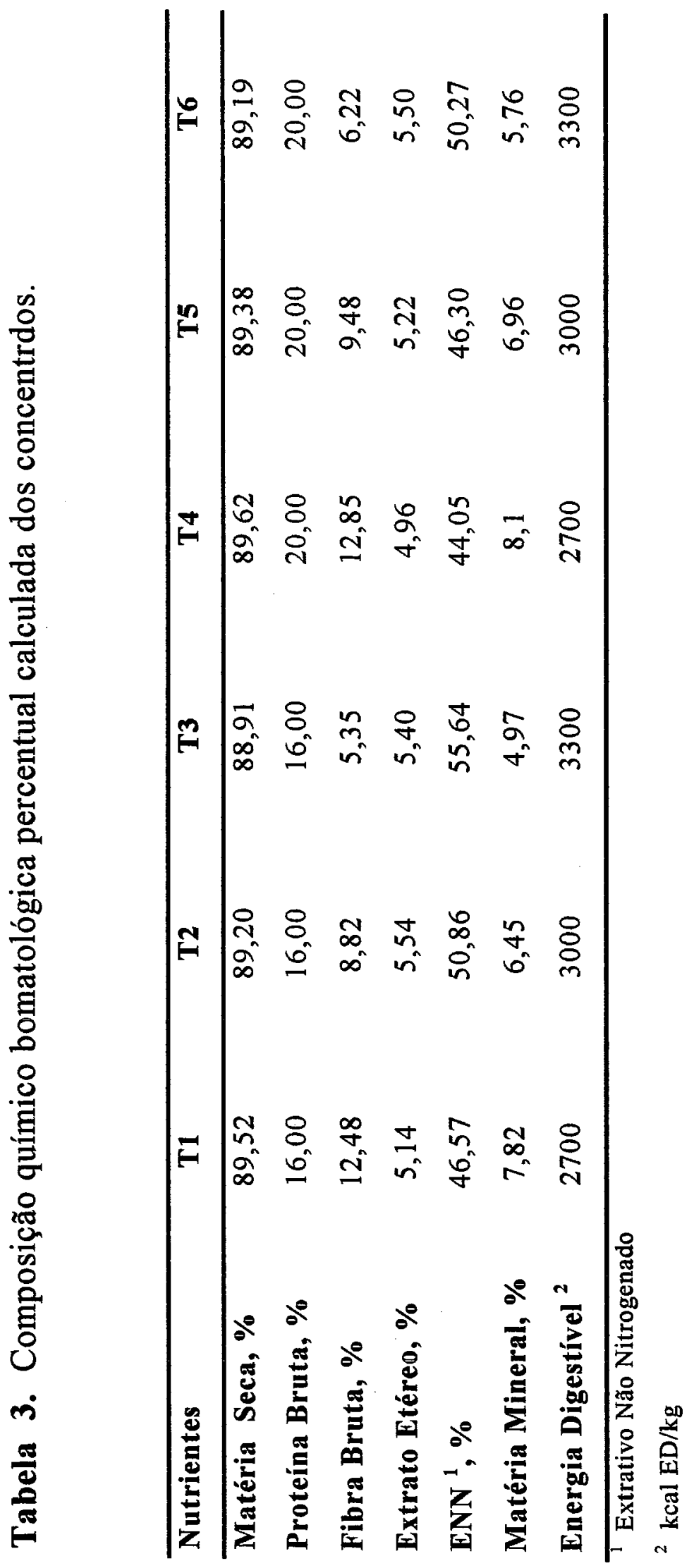




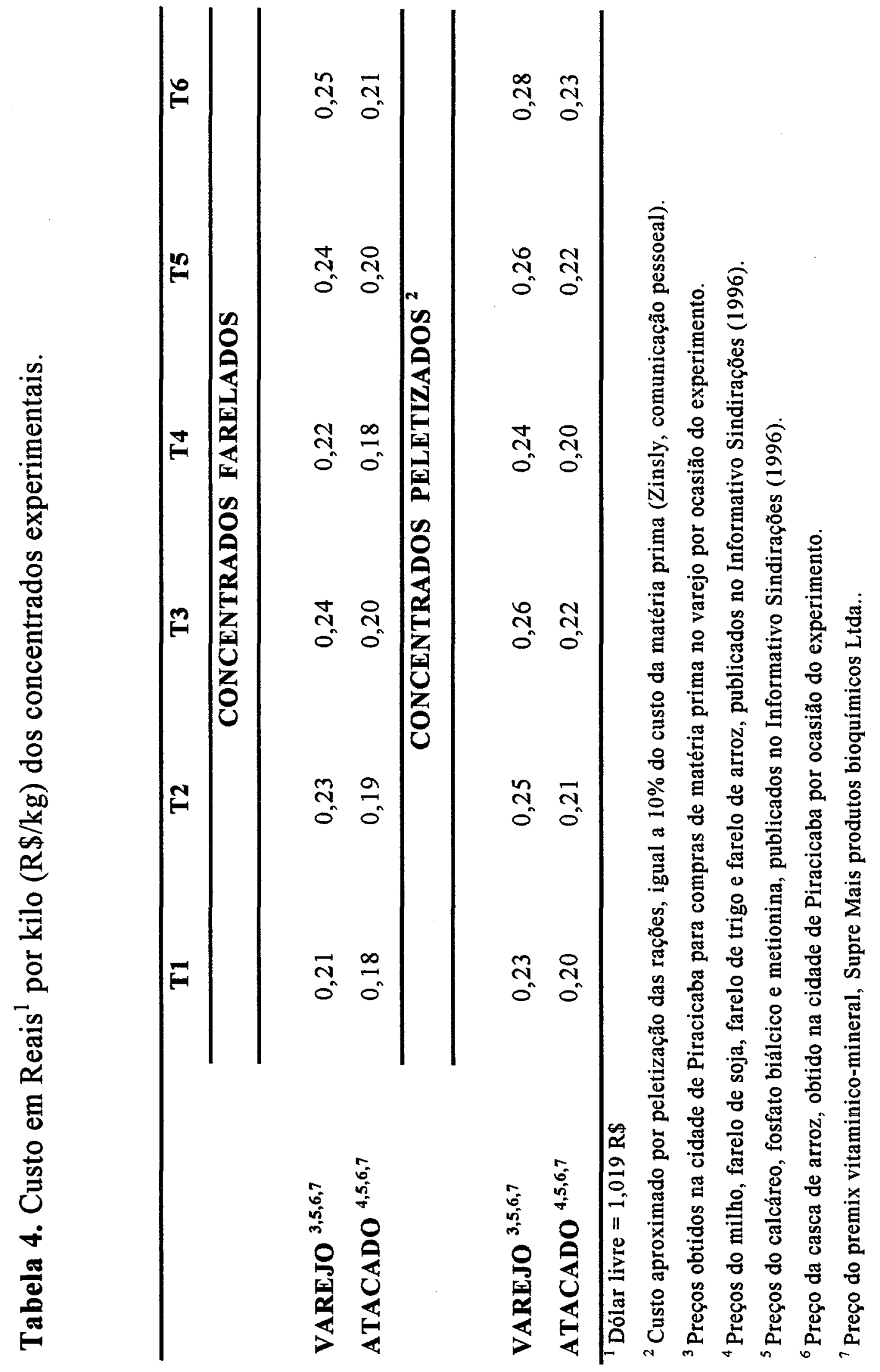




\section{RESULTADOS E DISCUSSÃO}

\subsection{Ganho diário de peso}

Na Tabela 5 são apresentadas as médias de ganho diário de peso para os níveis de energia, níveis de proteína e forma física do concentrado.

Tabela 5. Efeito dos tratamentos sobre o ganho diário de peso expresso em gramas.

\section{Concentrado Farelado Concentrado Peletizado}

$\begin{array}{lllll}\text { Níveis de Energia } & 16 \% \text { PB } & 20 \% \text { PB } & 16 \% \text { PB } & 20 \% \text { PB }\end{array}$

$2.700 \mathrm{kcal} \mathrm{ED} / \mathrm{kg} \quad 30,50^{\mathrm{abc}}$

$26,42^{\mathrm{c}}$

$36,61^{\mathrm{a}}$

$35,21^{a b}$

$3.000 \mathrm{kcal}$ ED/kg $\quad 31,39^{\mathrm{abc}}$

$33,36^{\mathrm{abc}}$

$33,17^{\mathrm{abc}}$

$36,90^{\mathrm{a}}$

$3.300 \mathrm{kcal} \mathrm{ED} / \mathrm{kg}$

$27,93^{\mathrm{c}}$

$31,58^{\mathrm{abc}}$

$28,72^{\text {bc }}$

$35,12^{\text {ab }}$

$\overline{\mathrm{a}, \mathrm{b}, \mathrm{c}}$ Médias com letras diferentes diferem entre si pelo teste SNK $(\mathrm{P}<0,05)$. 
Verifica-se diferenças significativas $(P<0,05)$ entre os varios tratamentos, sendo estas diferenças mais evidentes quando comparamos os tratamentos T5P (3.000 cal $\mathrm{Ed} / \mathrm{kg}$ e $20 \% \mathrm{~PB})$ e T1P $(2.700 \mathrm{kcal} \mathrm{Ed} / \mathrm{kg}$ e $16 \% \mathrm{~PB})$ com os tratamentos T3F e T4F (3.300 kcal ED/kg e 16\% PB, e $2.700 \mathrm{kcal} \mathrm{ED} / \mathrm{kg}$ e $20 \%$ de PB respectivamente).

A análise da variância (Tabela 6) revelou a existência de efeitos significativos $(P<0,05)$ para os níveis de energia, forma fisica do concentrado e as interações entre os níveis de energia e níveis de proteína e níveis de energia com a forma fisica do concentrado sobre o ganho de peso, não tendo sido significativos os efeitos dos níveis de proteina e a interação dos níveis de proteína e forma fisica do concentrado.

Para o desmembramento dos níveis de energia em polinômios ortogonais, o efeito quadrático para a regressão se mostrou significativo $(\mathrm{P}<0,05)$.

\subsubsection{Efeito dos níveis de energia}

Os efeitos das médias dos niveis de energia e suas interações com os de proteína e a forma física se encontram nas Tabelas 7 e 8, respectivamente.

Para os niveis de energia pode-se observar a existência de diferença significativa $(P<0,05)$ entre o nível de $3.000 \mathrm{kcal} \mathrm{ED/kg}(33,69 \mathrm{~g} / \mathrm{dia})$ e o nível $3.300 \mathrm{kcal}$ $\mathrm{ED} / \mathrm{kg}(30,73 \mathrm{~g} / \mathrm{dia}) . \mathrm{O}$ nível $2.700 \mathrm{kcal} \mathrm{ED} / \mathrm{kg}(32,14 \mathrm{~g} /$ dia $)$ não apresentou diferenças para o ganho diário de peso quando comparado com os outros níveis. 
Tabela 6. Análise de variância do ganho diário de peso.

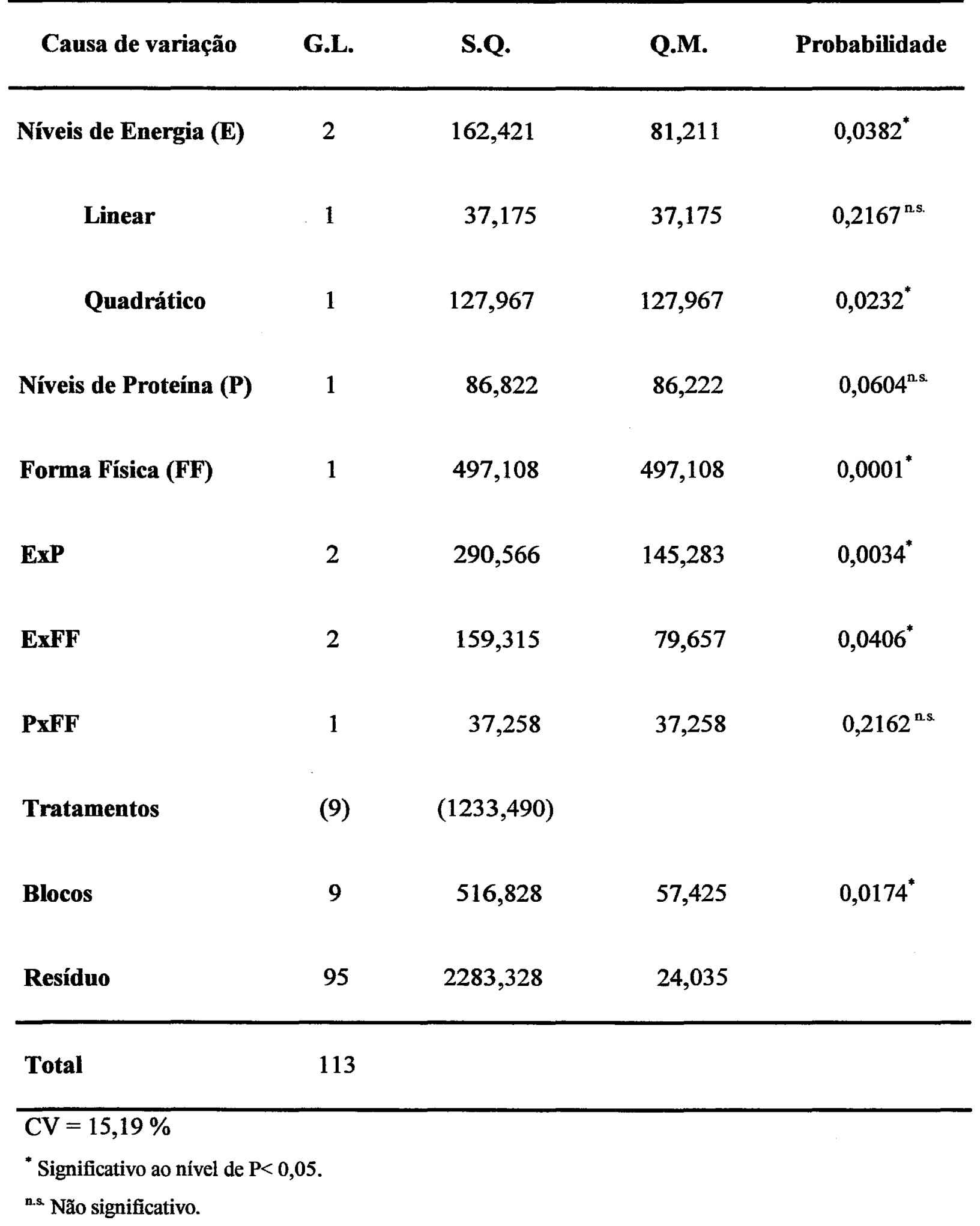


Tabela 7. Efeito dos níveis de energia e proteína sobre o ganho diário de peso expresso em gramas.

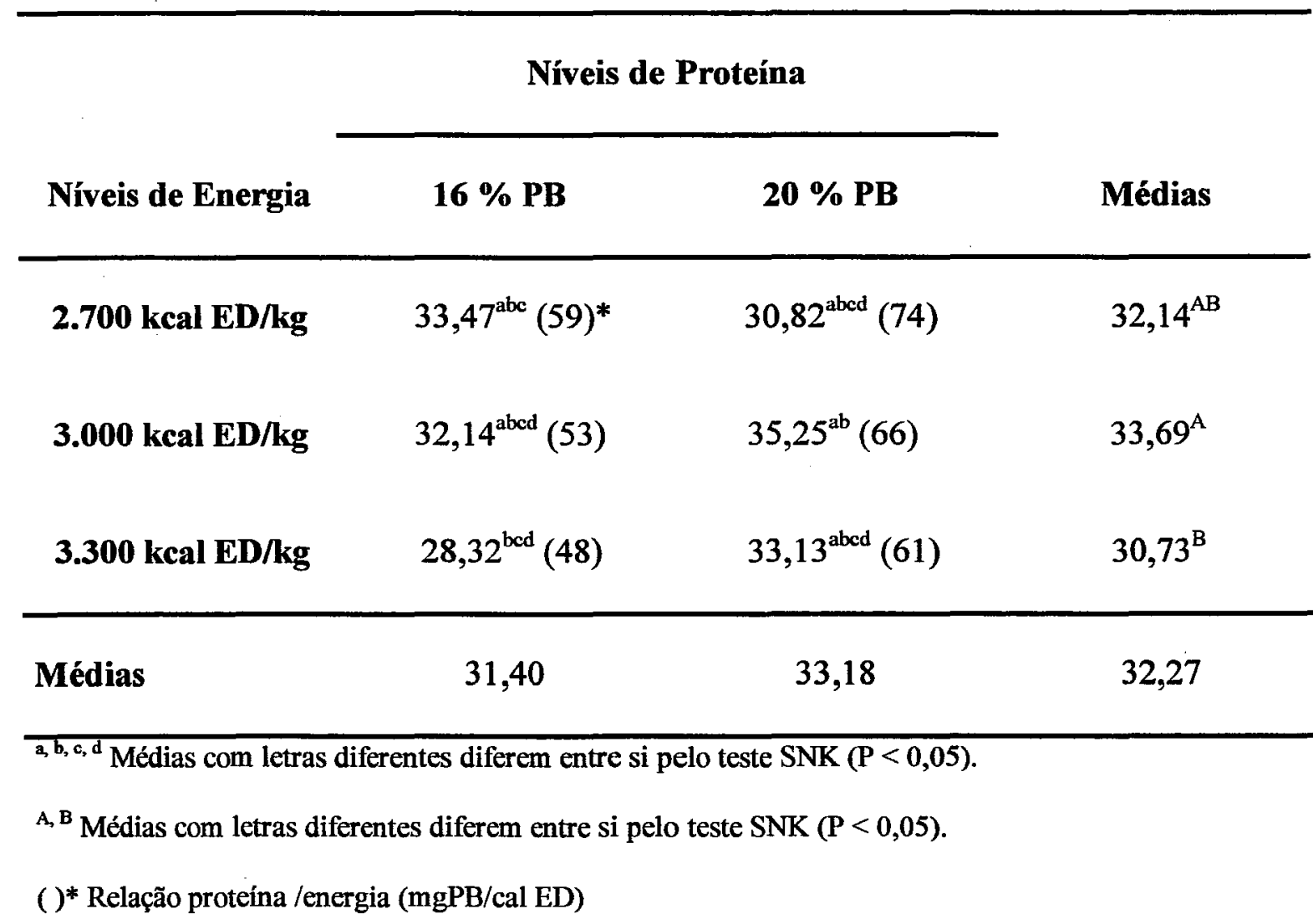

Quando se observa a interação entre os níveis de energia e proteína, nota-se uma tendência de um melhor desempenho quando a relação proteína:energia se apresenta próxima a $63 \mathrm{mg} \mathrm{PB} / \mathrm{cal} \mathrm{ED}$, valor este próximo a aqueles citados na literatura (Cheeke, 1987; Maertens et al., 1989 e Scapinello et al., 1995). Entretanto é interessante ressaltar que os valores encontrados em outros trabalhos são referentes a experimentos onde se utilizou rações peletizadas completas, enquanto que os valores encontrados neste experimento, referem-se a um alimento concentrado suplementado com rami, o que 
poderia mudar esta relação quando levada em consideração a quantidade de rami consumida e a composição quimica bromatológica do mesmo.

Tabela 8. Efeito dos níveis de energia e forma física sobre o ganho diário de peso expresso em gramas.

\section{Forma Física do Concentrado}

Níveis de Energia

Farelado

Peletizado

Médias

$2.700 \mathrm{kcal} \mathrm{ED} / \mathrm{kg}$

$28,37^{\text {bc }}$

$35,91^{\mathrm{ab}}$

$32,14^{\mathrm{AB}}$

$3.000 \mathrm{kcal} \mathrm{ED} / \mathrm{kg}$

$32,35^{\mathrm{abc}}$

$35,03^{\mathrm{ab}}$

$33,69^{A}$

$3.300 \mathrm{kcal}$ ED/kg

$29,54^{\text {be }}$

$31,92^{\text {abc }}$

$30,73^{\mathrm{B}}$

Médias

$30,03^{B}$

$34,29^{4}$

32,27

a, $b, c$ Médias com letras diferentes diferem entre si pelo teste $\operatorname{SNK}(\mathrm{P}<0,05)$.

${ }^{A},{ }^{B}$ Médias com letras diferentes diferem entre si pelo teste $\operatorname{SNK}(P<0,05)$.

${ }^{A, B}$ Médias com letras diferentes diferem entre si pelo teste SNK $(\mathrm{P}<0,05)$.

Em relação à interação entre os níveis de energia e a forma física do concentrado pode-se verificar um melhor desempenho $(\mathrm{P}<0,05)$ para os concentrados peletizados em relação aos similares farelados; isto evidencia a preferência dos animais por rações peletizadas, resultado este de acordo com Lebas (1988). Os resultados se 
apresentam semelhantes a aqueles obtidos por Wang et al. (1984), onde se observou uma maior velocidade no ganho de peso quando utilizados concentrados peletizados.

De forma geral observa-se uma tendência em se obter melhores resultados de ganho de peso quando usado o nível $3.000 \mathrm{kcal} \mathrm{ED} / \mathrm{kg}$ de concentrado, o que pode estar acontecendo por existir um balanceamento mais adequado de nutrientes para o sistema de alimentação adotado no presente trabalho, ou seja, concentrado mais rami.

\subsubsection{Efeitos dos níveis de proteína}

A análise da variância mostrada na Tabela 11 , não apresentou diferença significativa entre os níveis de proteína, mas os níveis utilizados neste experimento, se encontram próximos aos relacionados na literatura e evidenciados na revisão bibliográfica (Lebas, 1973a; Carregal \& Nikuma, 1980; Omole, 1980; Abdella et al.,1988; Coan et al., 1988). Cabe ressaltar a necessidade de se testar um maior número de níveis de proteína e uma maior amplitude dos extremos, com o intuito de se obter um resultado mais preciso em relação às condições em que foi conduzido este experimento.

Como foi discutido anteriormente, o efeito significativo da interação entre os niveis de energia e os de proteína se encontra diretamente relacionado com o balanço de proteína e energia da dieta, devendo ser melhor estudada a relação entre ambos e o efeito da suplementação com rami ou outro volumoso. 
A Tabela 9 apresenta os valores de ganho diário de peso para os níveis de proteína, forma física do concentrado e a sua interação, não tendo sido significativas as diferenças entre as médias.

Evidencia-se tendência de melhor desempenho dos animais alimentados com concentrados peletizados, o que pode ser explicado pelas preferências alimentares do coelho, citadas anteriormente.

Tabela 9. Efeito dos níveis de proteína e forma fisica sobre o ganho diário de peso expresso em gramas.

Forma Física do Concentrado

Níveis de Proteina

Farelado

Peletizado

Médias

$16 \%$

29,78

32,83

33,18

$20 \%$

30,39

35,74

31,40

Médias

$30,03^{a}$

$34,29^{b}$

32,27

${ }^{\mathrm{a}, \mathrm{b}}$ Médias com letras diferentes diferem entre si pelo teste SNK $(\mathrm{P}<0,05)$. 


\subsubsection{Efeito da forma física do concentrado}

As médias de ganho de peso para forma fisica do concentrado são apresentadas na Tabela 9, e podem ser explicadas pelo exposto anteriormente.

Já as médias da forma física e sua interaçào com os níveis de energia (Tabela 8), mostram uma tendência a um melhor desempenho $(\mathrm{P}<0,05)$ para os concentrados peletizados dos que apresentam menores níveis de energia quando comparados aos tratamentos que receberam concentrados farelados com níveis de energia de $2.700 \mathrm{kcal}$ $\mathrm{ED} / \mathrm{kg}$ e $3.300 \mathrm{kcal} \mathrm{ED} / \mathrm{kg}$.

\subsection{Consumo diário de concentrado}

Na Tabela 10 encontram-se os valores médios de consumo diário de concentrado para cada tratamento. Nota-se uma grande amplitude de variação entre o consumo diário de concentrado entre os tratamentos.

Dentre os tratamentos estudados, aqueles na forma farelada que possuiam o menor nível de energia foram os que apresentaram um maior consumo de concentrado $(\mathrm{P}<0,05)$ sendo 114,18 e $116,28 \mathrm{~g}$ respectivamente para os tratamentos T1F e T4F. O menor consumo diário de concentrado foi obtido para o tratamento T3P $(65,18 \mathrm{~g})$, tendo sido este significativamente menor aos demais. 
Observando as médias de consumo diário de concentrado dos diferentes tratamentos pode-se inferir um efeito dos tratamentos estudados sobre o consumo, evidenciando a influência desses fatores sobre a regulação da quantidade de alimento ingerido diariamente pelo animal.

A análise da variância para o consumo diário de concentrado é apresentada na Tabela 11, e mostra o efeito significativo dos níveis de energía, proteína e da forma fisica do concentrado $(\mathrm{P}<0,05)$.

Tabela 10. Efeito dos tratamentos sobre o consumo diário de concentrado expresso em gramas.

\begin{tabular}{|c|c|c|c|c|}
\hline \multirow[b]{2}{*}{ Niveis de Energia } & \multicolumn{2}{|c|}{ Concentrado Farelado } & \multicolumn{2}{|c|}{ Concentrado Peletizado } \\
\hline & $16 \% \mathrm{~PB}$ & $20 \%$ PB & $16 \%$ PB & $20 \% \mathrm{~PB}$ \\
\hline $2.700 \mathrm{kcal}$ ED/kg & $114,18^{\mathrm{a}}$ & $116,28^{a}$ & $102,53^{\mathrm{ab}}$ & $101,99^{\mathrm{ab}}$ \\
\hline $3.000 \mathrm{kcal}$ ED/kg & $99,73^{\mathrm{ab}}$ & $100,55^{\mathrm{ab}}$ & $84,74^{\text {bed }}$ & $96,09^{\mathrm{abc}}$ \\
\hline $3.300 \mathrm{kcal} \mathrm{ED} / \mathrm{kg}$ & $74,86^{\mathrm{dc}}$ & $82,82^{\text {bcd }}$ & $65,18^{d}$ & $84,28^{\text {bcd }}$ \\
\hline
\end{tabular}

Para os níveis de energia, quando decompostos, houve significância $(\mathrm{P}<0,05)$ para a regressão linear. 
Tabela 11. Análise de variância do consumo diário de concentrado.

\begin{tabular}{|c|c|c|c|c|}
\hline Causa de variação & G.L. & S.Q. & Q.M. & Probabilidade \\
\hline Níveis de Energia (E) & 2 & $19.573,128$ & $9.786,564$ & $0,0001^{*}$ \\
\hline Linear & 1 & $19.461,466$ & $19.461,466$ & $0,0001^{*}$ \\
\hline Quadrático & 1 & 179,116 & 179,116 & $0,4211^{\text {n.s. }}$ \\
\hline Níveis de Proteína (P) & 1 & $1.379,897$ & $1.379,897$ & $0,0272^{*}$ \\
\hline Forma Física (FF) & 1 & $2.136,634$ & $2.136,634$ & $0,0064^{*}$ \\
\hline ExP & 2 & 689,194 & 344,597 & $0,2895^{\text {n.s. }}$ \\
\hline ExFF & 2 & 433,293 & 216,647 & $0,4570^{\text {ns. }}$ \\
\hline PxFF & 1 & 246,481 & 246,481 & $0,3456^{\mathrm{ns.}}$ \\
\hline Tratamentos & (9) & $(24.458,627)$ & & \\
\hline Blocos & 9 & $6.722,472$ & 746,941 & $0,0072^{*}$ \\
\hline Resíduo & 95 & $26.065,662$ & 274,375 & \\
\hline Total & 113 & & & \\
\hline \multicolumn{5}{|l|}{$\mathrm{CV}=17,70 \%$} \\
\hline
\end{tabular}


A análise da variância não apresentou efeito significativo para as interações entre os níveis de energia, proteína e a forma física do concentrado.

\subsubsection{Efeitos dos níveis de energia}

Os valores médios do consumo diário de concentrado para os níveis de energia e as interações com os níveis de proteína e forma física, encontram-se nas Tabelas $12 \mathrm{e}$ 13.

Como pode ser observado, o consumo diário de concentrado foi influenciado pelo teor energético da dieta, tendo apresentado neste experimento médias menores de consumo $(P<0,05)$ para os níveis maiores de energia do concentrado, mostrando que o coelho é capaz de regular o seu consumo de ração de acordo com a quantidade energética ingerida.

Esta tendência de diminuição do consumo a medida que se aumenta o teor de energia da dieta, é apresentada na revisão bibliográfica e está de acordo com o conceito apresentado por diversos autores (Parigi-Bini, 1968; Lebas, 1975; Butcher et al., 1983).

Mesmo a análise da variância não tendo apontado efeito significativo para as interações entre níveis de energia e níveis de proteína, observa-se que dentro de cada nivel de proteína também ocorre a diminuiçào do consumo a medida que aumentamos o teor energético da dieta. 
O mesmo efeito da diminuição de consumo pode ser observado para a forma fisica do concentrado quando se avaliam os níveis de energia dento de cada forma (farelada ou peletizada).

Tabela 12. Efeito dos níveis de energía e proteína sobre o consumo diário de concentrado expresso em gramas.

Níveis de Proteína

\begin{tabular}{lccc} 
& $16 \%$ PB & $20 \%$ PB & Médias \\
\cline { 2 - 3 } Níveis de Energia & 108,35 & 109,13 & $108,74^{\mathrm{A}}$ \\
\hline $3.700 \mathrm{kcal} \mathrm{ED} / \mathrm{kg}$ & 91,59 & 98,95 & $95,27^{\mathrm{B}}$ \\
$3.000 \mathrm{kcal} \mathrm{ED} / \mathrm{kg}$ & 70,02 & & $76,45^{\mathrm{C}}$ \\
\hline Médias & $89,63^{\mathrm{a}}$ & 82,89 & 93,59 \\
\hline
\end{tabular}

${ }^{2, b}$ Médias com letras diferentes diferem entre si pelo teste SNK $(\mathrm{P}<0,05)$.

${ }^{\text {A, B, C }}$ Médias com letras diferentes diferem entre si pelo teste $\mathrm{SNK}(\mathrm{P}<0,05)$.

É interessante destacar que mesmo o comportamento do consumo diário de concentrado estando de acordo com outros dados encontrados na literatura, faz-se necessário lembrar que os valores aqui apresentados não levam em consideração o 
consumo diário de volumoso, o que seria de grande valia para conhecer a quantidade total de alimento ingerido pelo animal e que para as condições deste experimento, devido à estação do ano (inverno seco), durante a maior parte do periodo experimental o volumoso fornecido encontrava-se aquém do seu valor nutritivo médio apresentado na literatura (Echeverri, 1960; Nascimento, 1993).

Tabela 13. Efeito dos níveis de energía e forma física sobre o consumo diário de concentrado expresso em gramas.

\section{Forma Física do Concentrado}

\begin{tabular}{|c|c|c|c|}
\hline Niveis de Energia & Farelado & Peletizado & Médias \\
\hline $2.700 \mathrm{kcal}$ ED/kg & 115,23 & 102,26 & $108,74^{\mathrm{A}}$ \\
\hline $3.000 \mathrm{kcal}$ ED/kg & 100,12 & 90,42 & $95,27^{\mathrm{B}}$ \\
\hline 3.300 kcal ED/kg & 78,18 & 74,73 & $76,45^{\mathrm{C}}$ \\
\hline Médias & $98,54^{\mathrm{a}}$ & $89,13^{b}$ & 93,59 \\
\hline
\end{tabular}

Sabendo-se que a temperatura é outro fator que influencia o consumo de alimento por parte do animal, e a melhor qualidade e maior quantidade de volumoso 
encontrada no verão, pode-se prever que os resultados seriam diferentes e talvéz mais promissores nesta época do ano, havendo a necessidade da determinação do consumo de concentrados com diferentes teores energéticos suplementadas com volumosos nas duas épocas bem definidas do ano.

\subsubsection{Efeitos dos níveis de proteína}

As médias de consumo diário de concentrado para os niveis de proteína e forma fisica do concentrado se encontram na Tabela 14.

Como pode ser observado, para os concentrados contendo o nivel $20 \%$ de PB houve um maior consumo $(\mathrm{P}<0,05)$ do que aquele apresentado pelo nível $16 \%(97,70 \mathrm{e}$ $89,63 \mathrm{~g}$, respectivamente).

De maneira semelhante aos resultados obtidos por Lebas (1973a), foi observado maior consumo de concentrado para o nível mais elevado de proteína.

\subsubsection{Efeito da forma física da concentrado}

Em relaçào à forma física, houve diferenças significativas ao nível de $\mathrm{P}<0,05$, com referência ao consumo diário de alimento concentrado, mostrando maior consumo para a forma farelada $(98,54 \mathrm{~g})$ em relaçào a forma peletizada $(89,13 \mathrm{~g})$, contradizendo em parte o fato do animal preferir alimento na forma peletizada. $\mathrm{Na}$ realidade, esse 
maior consumo de alimento farelado é devido ao desperdicio de concentrado por parte dos animais, quer pela seleção dos alimentos dentro da mistura, quer seja pela recusa do animal a ingerir esse tipo de alimento, e neste ponto, é lícito admitir-se para certos animais comportamento de rejeição ao alimento farelado, o que mesmo não sendo regra geral, foi observado durante o periodo experimental com alguns animais.

Tabela 14. Efeito dos níveis de proteína e forma física sobre o consumo diário de concentrado expresso em gramas.

\section{Forma Física do Concentrado}

$\begin{array}{llll}\text { Níveis de Proteína } & \text { Farelado } & \text { Peletizado } & \text { Médias }\end{array}$

$\begin{array}{llll}16 \% & 95,82 & 84,15 & 89,63^{\mathrm{A}}\end{array}$

$\begin{array}{llll}20 & 99 & 94,12 & 97,70^{\mathrm{B}}\end{array}$

$\begin{array}{llll}\text { Médias } & 98,54^{\mathrm{a}} & 89,13^{\mathrm{b}} & 93,59\end{array}$

\footnotetext{
a,b Médias com letras diferentes diferem entre si pelo teste SNK $(\mathrm{P}<0,05)$.

${ }^{\mathrm{A}, \mathrm{B}}$ Médias com letras diferentes diferem entre si pelo teste SNK $(\mathrm{P}<0,05)$.
}

É interessante destacar que os valores de consumo de concentrado farelado ligada à elevada taxa de desperdicio ou perdas citadas em outros experimentos não foram 
verificadas neste trabalho, mas sim apenas e como ja citado, alguns casos esporádicos de animais que recusam o concentrado farelado.

Entretanto, não foram encontrados trabalhos na literatura utilizando concentrados próprios para coelhos, na forma farelada e suplementados com forragens verdes e sim apenas com rações completas na forma farelada ou com rações de outras espécies oferecidas aos coelhos em quantidades restritas. Por este raciocinio é possível inferir-se que no caso das rações fareladas completas, o baixo teor de energia possa ter contribuido às elevadas perdas ou no caso deste experimento, é possível que exista um efeito na diminuiçào das perdas ligado à suplementação ou como dito anteriormente, ao elevado teor energético dos concentrados, evidenciado pelo maior consumo de aqueles com níveis de $2.700 \mathrm{kcal} \mathrm{ED/kg}$.

\subsection{Conversão alimentar}

Os valores médios de conversão alimentar para cada um dos tratamentos encontram-se na Tabela 15.

Dentre os valores médios obtidos para a conversão alimentar para cada um dos tratamentos, destacam-se dois por apresentarem valores extremos e significativamente diferentes a todos os outros $(\mathrm{P}<0,05)$, o maior valor $(4,46)$ pertence ao tratamento T4F e o menor valor (melhor) ao tratamento T3P com 2,29.

A análise da variância para a conversão alimentar se encontra na Tabela 16. 
Tabela 15. Efeito dos tratamentos sobre a conversão alimentar expresso em $\mathrm{kg}$ de concentrado por $\mathrm{kg}$ de ganho de peso vivo.

\begin{tabular}{llccc}
\hline & \multicolumn{2}{c}{ Concentrado Farelado } & \multicolumn{2}{c}{ Concentrado Peletizado } \\
\cline { 2 - 5 } Níveis de Energia & $16 \% \mathrm{~PB}$ & $20 \% \mathrm{~PB}$ & $16 \% \mathrm{~PB}$ & $20 \% \mathrm{~PB}$ \\
\hline $2.700 \mathrm{kcal} \mathrm{ED} / \mathrm{kg}$ & $3,85^{\mathrm{b}}$ & $4,46^{\mathrm{a}}$ & $2,79^{\mathrm{cd}}$ & $2,91^{\mathrm{cd}}$ \\
$3.000 \mathrm{kcal} \mathrm{ED} / \mathrm{kg}$ & $3,22^{\mathrm{c}}$ & $3,04^{\mathrm{cd}}$ & $2,58^{\mathrm{cd}}$ & $2,66^{\mathrm{cd}}$ \\
$3.300 \mathrm{kcal} \mathrm{ED} / \mathrm{kg}$ & $2,74^{\mathrm{cd}}$ & $2,62^{\mathrm{cd}}$ & $2,29^{\mathrm{dd}}$ & $2,42^{\mathrm{cd}}$ \\
\hline
\end{tabular}

${ }^{\text {abc }}$ Médias com letras diferentes diferem entre si pelo teste SNK $(\mathrm{P}<0,05)$.

Como pode verificar-se, as causas para a variação para a conversão alimentar que tiveram efeito significativo foram: o nível de energia, a forma física do concentrado e a interação entre esses dois fatores.

Os níveis de proteina, assim como as interações onde teve participação não tiveram efeito significativo para a conversão alimentar.

Houve um efeito linear dos níveis de energia para a conversão alimentar.

Por ser uma variável resultante da relação entre outras duas, é possível que a conversão alimentar apresente efeitos semelhantes aos obtidos com as variáveis 
Tabela 16. Análise de variância da conversão alimentar.

\begin{tabular}{|c|c|c|c|c|}
\hline Causa de variação & G.L. & S.Q. & Q.M. & Probabilidade \\
\hline Níveis de Energia (E) & 2 & 18,853 & 9,426 & $0,0001^{*}$ \\
\hline Linear & 1 & 18,257 & 18,257 & $0,0001^{*}$ \\
\hline Quadrático & 1 & 0,470 & 0,470 & $0,2513^{\text {ns. }}$ \\
\hline Níveis de Proteína (P) & 1 & 0,348 & 0,348 & $0,3229^{\text {n.s. }}$ \\
\hline Forma Física (FF) & 1 & 14,688 & 14,688 & $0,0001^{*}$ \\
\hline $\operatorname{ExP}$ & 2 & 0,881 & 0,441 & $0,2914^{\text {n.s. }}$ \\
\hline ExFF & 2 & 5,197 & 2,598 & $0,0011^{*}$ \\
\hline PxFF & 1 & 0,0003 & 0,0003 & $0,9767^{\text {ns. }}$ \\
\hline Tratamentos & (9) & $(39,9673)$ & & \\
\hline Blocos & 9 & 2,560 & 0,284 & $0,6115^{\text {ns. }}$ \\
\hline Resíduo & 95 & 33,509 & 0,353 & \\
\hline
\end{tabular}

Total

$\mathrm{CV}=20,04 \%$

"Significativo ao nível de $\mathrm{P}, 0,05$.

${ }^{\text {ns. }}$ Não significativo. 
anteriormente expostas, sendo a explicação para o comportamento da conversão aliementar a interação entre o ganho de peso e o consumo de alimento.

\subsubsection{Efeito dos níveis de energia}

Os valores médios de conversão alimentar para os níveis de energia e suas interações se encontram nas Tabelas 17 e 18.

Como pode-se observar, para a conversão alimentar, os níveis de energia agem no sentido de diminuir os valortes da conversão a medida que aumenta o teor energético da dieta $(\mathrm{P}<0,05)$. Como pode ser observado há uma grande influência da diminuição do consumo de concentrado, mais do que do ganho de peso.

Observando os valores da interação dos níveis de energia com a forma física do concentrado, nota-se que além da influência do maior consumo de concentrado por parte daqueles animais tratados com concentrados farelados, há também uma influência do menor ganho de peso alcançado por estes animais, tenha acarretando em maior numero de dias para alcançar o peso de abate e maior custo do ítem alimentação no preço do produto final, quando comparando concentrados com diferentes níveis de energia dentro de uma mesma forma fisica.

Deve-se ressaltar mais uma vez que apesar do presente experimento, ter resultados semelhantres aos obtidos em outros, o mesmo se refere a valores de alimento concentrado, devendo-se levar em consideração que haverá valores maiores de consumo, 
e mesmo de conversão alimentar (sem significar necessariamente aumento nos valores de ganho de peso), quando computado o alimento volumoso suplementar.

Tabela 17. Efeito dos níveis de energía e proteína sobre a conversão alimentar expresso em $\mathrm{kg}$ de concentrado por $\mathrm{kg}$ de ganho de peso.

Níveis de Proteína

Níveis de Energia

$2.700 \mathrm{kcal}$ ED/kg

$3.000 \mathrm{kcal} \mathrm{ED} / \mathrm{kg}$

$3.300 \mathrm{kcal} \mathrm{ED} / \mathrm{kg}$

$20 \%$ PB

Médias

$16 \%$ PB

3,69

$3,51^{\mathrm{a}}$

3,33

2,86

$2,88^{\mathrm{b}}$

2,89

2,54

$2,52^{\mathrm{c}}$

Médias

2,91

3,03

2,96

${ }^{a, b, c}$ Médias com letras diferentes diferem entre si pelo teste SNK $(\mathrm{P}<0,05)$. 


\subsubsection{Efeito dos níveis de proteína}

Os níveis de proteína não excercem nenhuma influência sobre a conversão alimentar, sendo valores muito próximos e que não apresentam diferenças significativas entre si $(\mathrm{P}=0,3229)$. O mesmo ocorrendo com as interações em que participa a proteína.

Tabela 18. Efeito dos níveis de energía e forma fisica sobre a conversão alimentar expresso em $\mathrm{kg}$ de concentrado por $\mathrm{kg}$ de ganho de peso.

\section{Forma Física do Concentrado}

$\begin{array}{llll}\text { Níveis de Energia } & \text { Farelado } & \text { Peletizado }\end{array}$

$\begin{array}{llll}2.700 \mathrm{kcal} \mathrm{ED} / \mathrm{kg} & 4,17^{\mathrm{a}} & 2,85^{\mathrm{bcd}} & 3,51^{\mathrm{A}}\end{array}$

$3.000 \mathrm{kcal} \mathrm{ED} / \mathrm{kg} \quad 3,14^{\mathrm{bc}} \quad 2,62^{\mathrm{bcd}} \quad 2,88^{\mathrm{B}}$

$3.300 \mathrm{kcal} \mathrm{ED} / \mathrm{kg} \quad 2,69^{\mathrm{bed}} \quad 2,36^{\mathrm{cd}} \quad 2,52^{\mathrm{C}}$

Médias

$3,33^{4}$

$2,61^{B}$

2,96

$\overline{a, b, c, d}$ Médias com letras diferentes diferem entre si pelo teste SNK $(P<0,05)$.

A, B, C Médias com letras diferentes diferem entre si pelo teste $\operatorname{SNK}(\mathrm{P}<0,05)$.

${ }^{A, B}$ Médias com letras diferentes diferem entre si pelo teste SNK $(\mathrm{P}<0,05)$. 


\subsubsection{Efeito da forma física da concentrado}

Como dito anteriormente, este fator está ligado ao elevado consumo (inclusive perdas) dos concentrados farelados em relação às peletizados, e ao menor ganho de peso resultante nos animais alimentados com concentrados farelados.

A Tabela 19 mostra a existência de diferenças significativas $(P<0,05)$ para a forma física dentro da conversão alimentar.

Nota-se também que dentro da forma física não existem ditferenças para os niveis de proteína.

Tabela 19. Efeito dos níveis de proteína e forma fisica sobre a conversão alimentar expresso em $\mathrm{kg}$ de concentrado por $\mathrm{kg}$ de ganho de peso vivo.

\section{Forma Física do Concentrado}

$\begin{array}{llll}\text { Niviveis de Proteína } & \text { Farelado } & \text { Peletizado } & \text { Médias }\end{array}$

$16 \%$

3,27

2,55

2,91

$20 \%$

3,39

2,66

3,03

Médias

$3,33^{\mathrm{a}}$

$2,61^{b}$

2,96

${ }^{\mathrm{a}, \mathrm{b}}$ Médias com letras diferentes diferem entre si pelo teste SNK $(\mathrm{P}<0,05)$. 


\subsection{Mortalidade}

Entre os resultados mais importantes obtidos neste experimento encontra-se a baixa taxa de mortalidade, isto levando-se em consideração que foram utilizados alimentos concentrados, tendo alguns deles apresentado valores de fibra bruta inferiores aos níveis mínimos recomendados.

Observa-se na Tabela 20, a ocorrência de mortalidade apenas para os concentrados farelados, e principalmente o maior número no concentrado com os maiores níveis de energia e proteína (3.300 kcal ED/kg e $20 \%$ PB).

É interessante salientar que o concentrado que apresentou a maior taxa de mortalidade possui na sua composição $35,14 \%$ de milho, o que poderia explicar, em conjunto com a seleção de alimentos por parte do animal essa elevada taxa, apesar de não ter ocorrido mortalidade no tratamentro em que a percentagem de milho foi 50,12.

\subsection{Custo do alimento concentrado por $\mathrm{kg}$ de peso vivo}

Com base nos preços no atacado dos concentrados (Tabela 4) e a conversão alimentar de cada um dos tratamentos, foi calculado o custo da alimentação por $\mathrm{kg}$ de peso vivo (Tabela 21). 
Tabela 20. Taxa de mortalidade observada para cada um dos tratamentos expressa em percentagem.

\begin{tabular}{lcccc}
\hline & \multicolumn{2}{c}{ Concentrado Farelado } & \multicolumn{2}{c}{ Concentrado Peletizado } \\
\cline { 2 - 5 } Níveis de Energia & $16 \%$ PB & $20 \%$ PB & $16 \%$ PB & $20 \%$ PB \\
\hline $2.700 \mathrm{kcal} \mathrm{ED} / \mathrm{kg}$ & 10 & 0 & 0 & 0 \\
$3.000 \mathrm{kcal} \mathrm{ED} / \mathrm{kg}$ & 10 & 10 & 0 & 0 \\
$3.300 \mathrm{kcal} \mathrm{ED} / \mathrm{kg}$ & 0 & 30 & 0 & 0 \\
\hline
\end{tabular}

Nota-se que os concentrados peletizados mesmo com preço maior que os farelados, devido ao maior ganho de peso que proporcionam e ao menor consumo de concentrado, apresentam custo por $\mathrm{kg}$ de coelho vivo menor que os farelados.

Observa-se também e de forma bem evidente nos concentrados farelados 0 efeito do nível de energia no custo, isto acompanhando os resultados obtidos no consumo de alimento, e mostrando o efeito das perdas de concentrado no custo do animal.

É interessante destacar que o preço dos concentrados deste experimento foram de 56 a $88 \%$ do preço das rações comerciais encontradas no mercado varejista de Piracicaba, sendo de aproximadamente $\mathrm{R} \$ 0,32$, o que ajudaria a formular conclusões ao respeito da economia feita com a possível adoção deste sistema de alimentação (concentrado de concentrados + volumoso). Cabe também chamar a atenção ao fato da pesquisa de preços realizada mostrar preços das matérias primas acima dos preços encontrados historicamente, o que poderia resultar em uma diminuição dos custos. 
Tabela 21. Custo do alimento concentrado por $\mathrm{kg}$ de peso vivo ( $\mathrm{R} \$ / \mathrm{kgPV})$.

\begin{tabular}{lcccc}
\hline & \multicolumn{2}{c}{ Concentrado Farelado } & \multicolumn{2}{c}{ Concentrado Peletizado } \\
\cline { 2 - 5 } Níveis de Energia & $\mathbf{1 6} \% \mathrm{~PB}$ & $\mathbf{2 0} \% \mathrm{~PB}$ & $\mathbf{1 6} \% \mathrm{~PB}$ & $\mathbf{2 0} \% \mathrm{~PB}$ \\
\hline $\mathbf{2 . 7 0 0} \mathrm{kcal} \mathrm{ED} / \mathrm{kg}$ & 0,69 & 0,80 & 0,56 & 0,58 \\
$\mathbf{3 . 0 0 0} \mathrm{kcal} \mathrm{ED} / \mathrm{kg}$ & 0,61 & 0,61 & 0,54 & 0,59 \\
$\mathbf{3 . 3 0 0} \mathrm{kcal} \mathrm{ED} / \mathrm{kg}$ & 0,55 & 0,55 & 0,51 & 0,56 \\
\hline
\end{tabular}




\section{CONCLUSÕES}

Com base nos resultados obtidos neste experimento pode-se concluir que:

1) É possível a utilização do sistema alimentar aqui proposto, composto de concentrado com suplementação com alimento volumoso, como alternativa em criações comerciais.

2) Dentre as duas formas fisicas utilizadas, foram os concentrados peletizados os que apresentaram melhor desempenho por parte dos animais.

3) A o concentrado farelado apesar de ter resultado em menor desempenho por parte dos animais, mostrou-se ainda viável para utilização em criações comerciais.

4) $\mathrm{O}$ nível de energia $3.000 \mathrm{kcal} \mathrm{ED} / \mathrm{kg}$ de concentrado foi o que apresentou melhor desempenho por parte dos animais.

5) O nível de proteína de $16 \%$, propiciou um menor consumo de concentrado por parte dos animais, entretanto deveram ser estudados níveis em uma maior amplitude e levando em consideração o valor nutritivo do volumoso. 
6) $\mathrm{O}$ tratamento com $3.300 \mathrm{kcal} \mathrm{Ed} / \mathrm{kg}$ e $16 \%$ de proteína bruta apresentou menor custo de alimento por $\mathrm{kg}$ vivo de coelho produzido, mostrando o potencial deste sistema para abaixar os custos das criações comerciais de coelhos. 


\section{REFERÊNCIAS BIBLIOGRÁFICAS}

ABDELLA, H.M.; SHALASH, S.M.M.; BOULOS, N.Z.; SELIM, A.D. Effect on growing rabbits of feeding different levels of crude protein. The Journal of Applied Rabbit Research, v. 11, n. 4, p. 252-256, Oct./Dec. 1988.

AYYAT, M.S. Growth, feed efficiency and carcass traits of growing rabbits affected by levels of dietary protein and sulphur amino acids. Egyptian Journal of Rabbit Science, v. 1, n. 1, p. 1-12, 1991. / Resumo em CAB Abstracts on CD-ROM, v. 4A, 1993-94/.

BLAS, E; CERVERA, C.; FERNANDEZ-CARMONA, J. Effect of two diets with varied starch and fibre levels on the performances of 4-7 weeks old rabbits. World Rabbit Science, v. 2, n. 4, p. 117-121, Oct./Dec. 1994.

BUTCHER, C.; BRYANT, M.J.; OWEN, E.; LEACH, I.; MACHIN, D.H. The effect of slaughter weight upon the growth and carcass characteristics of rabbits fed diets of different dietary metabolizable energy concentrations. Animal Production, v. 37, p. 275-282, 1983.

CARREGAL, R.D.; NIKUMA, S. Niveis de proteína bruta em rações para coelhos em crescimento. Revista Latino-Americana de Cunicultura, v. 1, p. $37-40,1980$. 
CARREGAL ,R.D.; TOSI, H. PERECIN, D. Efeito da utilização do capim elefante na alimentação de ccoelhos em crescimento. In: REUNIÃO ANUAL DA SOCIEDADE BRASILEIRA DE ZOOTECNIA, 19., Piracicaba, 1982. Anais. Piracicaba: Sociedade Brasileira de Zootecnia, 1982. p. 250-251.

CASTELLO, J.A.; GURRI, A. Effects of energy levels in the feed and the feeding program on performances of growing rabbits. The Journal of Applied Rabbit Research, v. 15, p. 958-964, 1992. / Resumo em CAB Abstracts on CD-ROM, v. 4A, 1993-94/.

CHEEKE, P.R. Rabbit nutrition and feeding: recent advances and future perspectives. The Journal of Applied Rabbit Research, v. 7, n. 1, p. 31-37, Jan./Mar. 1984.

CHEEKE, P.R. Rabbit feeding and nutrition. Orlando: Academic Press, 1987. $376 \mathrm{p}$.

CHEEKE, P.R.; GROBNER, M.A.; PATTON, N.M. Fiber digestion and utilization in rabbits. The Journal of Applied Rabbit Research, v. 9, n. 1, p. 25-30, Jan./Mar. 1986.

COAN, M.A.; KELlOG, D.W.; NELSON, T.S.; DANIELS, L.B. Effect of dietary level of protein and methionine supplementation on growing rabbits. The Journal of Applied Rabbit Research, v. 11, n. 2, p. 84-86, Apr./June 1988. 
COLIN, M.; LEBAS, F. Rabbit meat production and consumption in the world. A synthesis attempt. In: JOURNÉES DE LA RECHERCHE CUNICOLE EN FRANCE, 6., La Rochelle, 1994. Abstracts. World Rabbit Science, v. 3, n. adicional, p. 16, 1995.

CORDOBA, J.A. El ramio en la alimentación animal. Agricultura Tropical, v. 17, n. 6 , jun. 1961 .

CRESPI, M.P.; COLL, J.F.; ITAGIBA, M.G.; LISEU, L.C.; CARNEIRO, O.M. Utilização do capim angola ( Brachiaria mutica) na alimentação de coelhos para corte. In: REUNIÃO ANUAL DA SOCIEDADE BRASILEIRA DE ZOOTECNIA, 21., Belo Horizonte, 1984. Anais. Belo Horizonte: Sociedade Brasileira de Zootecnia, 1984a. p. 259.

CRESPI, M.P.; COLL, J.F.; ITAGIBA, M.G.; LISEU, L.C.; CARNEIRO, O.M. Utilização do rami ( Bohemeria nivea) na alimentação de coelhos para corte. In: REUNIÃO ANUAL DA SOCIEDADE BRASILEIRA DE ZOOTECNIA, 21., Belo Horizonte, 1984. Anais. Belo Horizonte: Sociedade Brasileira de Zootecnia, 1984b. p. 260.

CRESPI, M.P.; COLL, J.F.; ITAGIBA, M.G.; LISEU, L.C.; SOUSA, J.C.; CARNEIRO, O.M. Utilização da folha de amoreira na alimentação de coelhos para corte. In: REUNIÃO ANUAL DA SOCIEDADE BRASILEIRA DE ZOOTECNIA, 23., Campo Grande, 1986. Anais. Campo Grande: Sociedade Brasileira de Zootecnia, 1986. p. 86.

ECHEVERRI, H.S. El ramio como forraje. Agricultura Tropical, v. 16, n. 11, p. 740-743, Nov. 1960. 
EL-HINDAWY, M.M.; YAMANI, K.A.; ESKANDAR, E.G. Growth performance, carcass traits and digestibility of rabbits as affected by breed and form of the diet under Egyptian environmenal conditions. Egyptian Journal of Rabbit Science, v. 2, n. 2, p. 185-196, 1992. / Resumo em CAB Abstracts on CD-ROM, v. 4A, 1993-94\%.

EL-KERDAWY, D.M.A.; RASHWAN, A.A.; IBRAHIM, H.; EL-GENDY, K.M. Digestibility, growth performance, carcass traits and some physiological aspects of growing New Zeland White rabbits as affected by partial substution of concentrates with carrot-tops hay and feeding times. Egyptian Journal of Rabbit Science, v. 2, n. 1, p. 61-71, 1992. / Resumo em CAB Abstracts on CD-ROM, v. 4A, 1993-94 /.

FARINU, G.O. Effect of feeding a compound diet based on non-conventional feedstuffs on growth and carcass characteristics of rabbits. World Rabbit Science, v. 2, n. 4, p. 123-126, Oct./Dec. 1994.

FEKETE, S.; GIPPERT, T. Digestibility and nutritive value of nineteen important feedstuffs for rabbits. The Journal of Applied Rabbit Research, v. 9, n. 3, p. 103-108, July/Sept. 1986.

FERREIRA, W.M.; FERREIRA, S.R.; CAVALCANTE, S.G. Antecedentes da pesquisa em nutrição e alimentação de coelhos e pequenos animais publicada no Brasil entre 1975 e 1994. In: REUNIÃO ANUAL DA SOCIEDADE BRASILEIRA DE ZOOTECNIA, 32., Brasília, 1995. Anais. Brasília: Sociedade Brasileira de Zootecnia, 1995. p. 367-381. 
HARRIS, D.J.; CHEEKE, P.R.; PATTON, N.M. Feed preference and growth performance of rabbits fed pelleted versus unpelleted diets. The Journal of Applied Rabbit Research, v. 6, n. 1, p. 15-17, Jan./Mar. 1983.

HARRIS, D.J.; CHEEKE, P.R.; PATTON, N.M. Effect on fryer rabbit performance of supplementing a pelleted diet with alfalfa or grass hay. The Journal of Applied Rabbit Research, v. 7, n. 4, p. 148-150, Oct./Dec. 1984.

HUANG, C.T.; LIAO, C.W.; LEE, M.S. Study on dietary crude protein and digestible energy requeriments of growing rabbits. Journal of Taiwan Livestock Research, v. 22, n. 2, p. 7-13, 1989. / Resumo em CAB Abstracts on CD-ROM, v. 3A, 1990-91/.

LEBAS, F. Effet de la teneur en protéines de rations a base de soja ou de sesame sur la croissance du lapin. Annalles de Zootechnie, v. 22, n. 1, p. 83-92, 1973a.

LEBAS, F. Possibilités d'alimentation du lapin en croissance avec des régimes présentés sous forme de farine. Annalles de Zootechnie, v. 22, n. 2, p. 249$251,1973 b$.

LEBAS, F. Influence de la teneur en énergie de l'aliment sur les performances de croissance chez le lapin. Annalles de Zootechnie, v. 24, n. 2, p. 281-288, 1975.

LEBAS, F. Rabbits. Licestock Production Science, v. 19, n. 1/2, p. 289-298, May 1988. 
LEE, M.J.; HUANG, H.H. Effects of meal and pellet feeds mixed with water on the performance of rabbits. Journal of the Taiwan Livestock Research, v. 17, n. 2, p. 231-239, 1984. / Resumo em CAB Abstracts on CD-ROM, v. $1,1984-86 /$.

LUKEFAHR, S.D.; CHEEKE, P.R. Rabbit project development strategies in subsistence farming systems. 2. Research applications. Revista Mundial de Zootecnia, v. 69, n. 4, p. 26-35, 1991.

MACHIN, D.H.; BUTCHER, C.; OWEN, E.; BRYANT, M.; OWEN, J.E. The effects of dietary metabolizable energy concentration and physical form of the diet on the performance of growing rabbits. In: CONGRESO MUNDIAL DE CUNICULTURA, 2., Barcelona, 1980. Memoria. Barcelona: Asociación Española de Cunicultura, 1980. Ponencia C, p. 65-75.

MENDES, A.A.; FUNARI, S.R.C.; NUNES, J.R.V.; SPERS, A. Níveis crescentes de feno de rami em rações para coelhos em crescimento. Revista Latino-Americana de Cunicultura, v. 1, p. 27-35, 1980.

MUTETIKKA, D.B.; CARLES, A.B.; WANYOIKE, M.M. The effect of level of supplementation to diets of rhodes grass ( Chloris gayana) hay, maize ( Zea mays ) leaves and sweet potato ( Ipomoea batatas ) vines on performance of grower rabbits. The Journal of Applied Rabbit Research, v. 13, p. 179183, 1990.

NASCIMENTO, M.C.L. Valor nutricional dos fenos de aveia (Avena strigosa, S. ) e de rami ( Bohemeria nivea, G. ) para coelhos em crescimento. Viçosa, 1993. 58 p. Dissertação (M.S.) - Universidade Federal de Viçosa. 
NATIONAL RESEARCH COUNCIL. Nutrient requirements of rabbits. Washington, National Academy of Science, 1977. 30p.

OMOLE, T.A. The effect of level of dietary protein on growth and reproductive performence in rabbits. The Journal of Applied Rabbit Research, v. 5, n. 3, p. 83-88, July/Sept. 1982.

ONIFADE, A.A.; TEWE, O.O. Alternative tropical energy feed resources in rabbit diets: growth performance, diet's digestibility and blood composition. World Rabbit Science, v. 1, n. 1, p. 17-24, Jan./Mar. 1993.

OWEN, J.E. La carne de conejo para los paises en desarrollo. Revista Mundial de Zootecnia, v. 39, p. 2-11, jul./sept. 1981.

PARIGI-BINI, R. Diete ad alta energia per conigli da carne. Rivista di Zootecnia, v. 3, p. 145-159, 1968.

PARIGI-BINI, R.; CHIERICATO, G.M. Utilizzazione di diete a basso contenuto di fibra per conigli in accrescimento. Rivista di Zootecnia e Veterinaria, v. 3, p. 203-212, mag./giu. 1974.

POISMANS, R.; WITTOUCK, P.J. Effects of a ration rich in protein and poor in cellulose on growth performance, organ development and carcass composition of the Termonde White rabbit. Annalles de Zootechnie, v. 35, n. 1, p. 6178, 1986. / Resumo em CAB Abstracts on CD-ROM, v. 1, 1984-86/. 
RAHARJO, Y.C.; CHEEKE, P.R.; PATTON, N.M. Evaluation of tropical forages and rice by-products as rabbit feeds. The Journal of Applied Rabbit Research, v. 11, n. 3, p. 201-211, July/Sept. 1988.

RASTOGI, R.K. A note on feed efficiency and cost of rabbit meat production in Trinidad. The Journal of Applied Rabbit Research, v. 9, n. 2, p. 67-68, Apr./June 1986.

RUFFINI-CASTROVILLI, C.;RIGONI, M. Dissociated feeding of rabbits: first results in young animals. Atti della Societa Italiana delle Scienze Veterinarie, v. 37, p. 480-483, 1983. / Resumo em CAB Abstracts on CDROM, v. 1, 1984-86/.

SANCHEZ, W. K. CHEEKE, P. R.; PATTON, N. M.. The use of chopped alfalfa rations with varying levels of molasses for weanling rabbits. Journal of Applied Rabbit Research, v. 7, n. 1, p. 13-16, Jan./Mar. 1984.

SANKHYAN, S.; TIWARI, S.P.; NARANG, M.P. Effects of different levels of protein and energy on the growth performance of rabbits. Journal of Applied Rabbit Research, v. 13, n. 2, p. 66-68, Apr./June 1990. / Resumo em CAB Abstracts on CD-ROM, v. 3A, 1990-91/.

SCAPINELLO, C.; TAFURI, M.L.; REGAZZI, A.J.; ROSTAGNO, H.S.; FURLAN, A.C. Níveis de proteína bruta e de energia digestível em dietas para coelhos Nova Zelândia Branco em crescimento. Revista da Sociedade Brasileira de Zootecnia, v. 24, n. 6, p. 992-1000, 1995. 
SINDICATO NACIONAL DA INDÚSTRIA DE ALIMENTAÇÃO ANIMAL. Persquisa de mercado elaborada pelo sindirações. Informativo Sindirações, n. 39, p. $4,1996$.

SONBOL, S.M.; EL-BAKI, S.M.A.; EL-GENDY, K.M.; MARAI, A.M.; ABDEL-BAKI, S.M. Effects of dietary protein level and sources on nutrient utilization and growth performance in New Zeland White rabbits. Egyptian Journal of Rabbit Science, v. 2, n. 2, p. 145-160, 1992. / Resumo em CAB Abstracts on CD-ROM, v. 4A, 1993-94/.

STATISTIC ANALYSIS SYSTEM INSTITUTE. User's guide: Basics. Cary, 1987.

TOLEDO, G.S.P.; ROSA, A.P.; BRUTTI, C.E.; PALOSCHI, J. Estudo de diferentes níveis de proteína bruta em rações fareladas para coelhos em crescimento no periodo de inverno. In: REUNIÃO ANUAL DA SOCIEDADE BRASILEIRA DE ZOOTECNIA, 31., Maringá, 1994. Anais. Maringá: Sociedade Brasileira de Zootecnia, 1994. p. 565.

WANG, N.T.; SHU, J.M.; GU, Z.J. Pellets for rabbits. Chinese Journal of Rabbit Farming Zhongguo Yangtu Zazhi, v. 1, p. 22-30, 1984. / Resumo em CAB Abstracts on CD-ROM, v. 1, 1984-86/.

ZINSLY, C.F. Eficiência dos fenos de rami e de soja perene na alimentação de coelhos. O Solo, v. 62, n. 1, p. 67-72, 1970. 